\title{
CFD assessment of multiple energy piles for ground source heat pump in heating mode
}

\author{
Yuanlong Cui ${ }^{\text {a, b }}$, Jie Zhu ${ }^{\text {a, * }}$ \\ ${ }^{a}$ Department of Architecture and Built Environment, The University of Nottingham, Nottingham \\ NG7 2RD, United Kingdom \\ ${ }^{\mathrm{b}}$ UK Greenergy Pathways Ltd, Queens Road, Nottinghamshire, NG9 2JW, United Kingdom
}

\begin{abstract}
A three-dimensional (3D) computational fluid dynamics (CFD) model of ground source heat pump (GSHP) with multiple energy piles (EPs) is developed to investigate the system heating performances under continuous and intermittent operating conditions, the system thermal energy outputs and coefficients of performance (COPs) are evaluated. The 3D model is meshed based on the hybrid grids with tetrahedron, hexahedron unstructured and structured types, and the k- $\varepsilon$ equations to describe the turbulence phenomena within U-tube are resolved by using computational fluid dynamics (CFD) software. A good agreement with less than $12 \%$ difference between the CFD model and experimental results is achieved. $10 \mathrm{~h}$ active and $14 \mathrm{~h}$ idle mode is adopted as the intermittent operating condition in this study. Based on the 3D model simulation data, it is found that the average monthly COPs of the intermittent operation are 3.63, 3.58, 3.45, 3.21, 3.25 and 3.34 from November to April respectively, which are corresponding to $9.3 \%, 9.5 \%, 7.1 \%, 5.9 \%, 4.8 \%$ and $3.1 \%$ increases relative to those of the continuous operation. Furthermore, the soil temperature under the intermittent operating condition is higher than that of the continuous operation. To sum up, the intermittent operation not only contributes to the soil temperature recovery but also improves the system performance, which is very favourable for the long-term operation.
\end{abstract}

Keywords: Energy piles, Ground heat exchangers, CFD model, Continuous operation, Intermittent operation.

\section{Introduction}

Energy pile (EP) can be utilized for building structural support and ground heat exchanger (GHE) for ground source heat pump (GSHP), which is one of the most promising renewable energy technologies due to its low cost and high efficiency [1,2]. Normally, a GSHP consists of three fundamental components: a GHE, a heat pump unit and an air duct network. Different GHE configurations involving single-, double-, triple U-tube, W-shaped tube, coaxial tube or helical-shaped tube and EPs are presented in Fig.1. Ground heat transfer surrounding the GHE is a key issue for the system design and performance evaluation. In order to clarify the influences of different parameters on the ground heat transfer, many experimental investigations are carried out with high costs. As a result, various two-

\footnotetext{
* Corresponding author. Tel: +44-115-8466141 Fax: +44-115-951315

E-mail address: jie.zhu@nottingham.ac.uk
} 


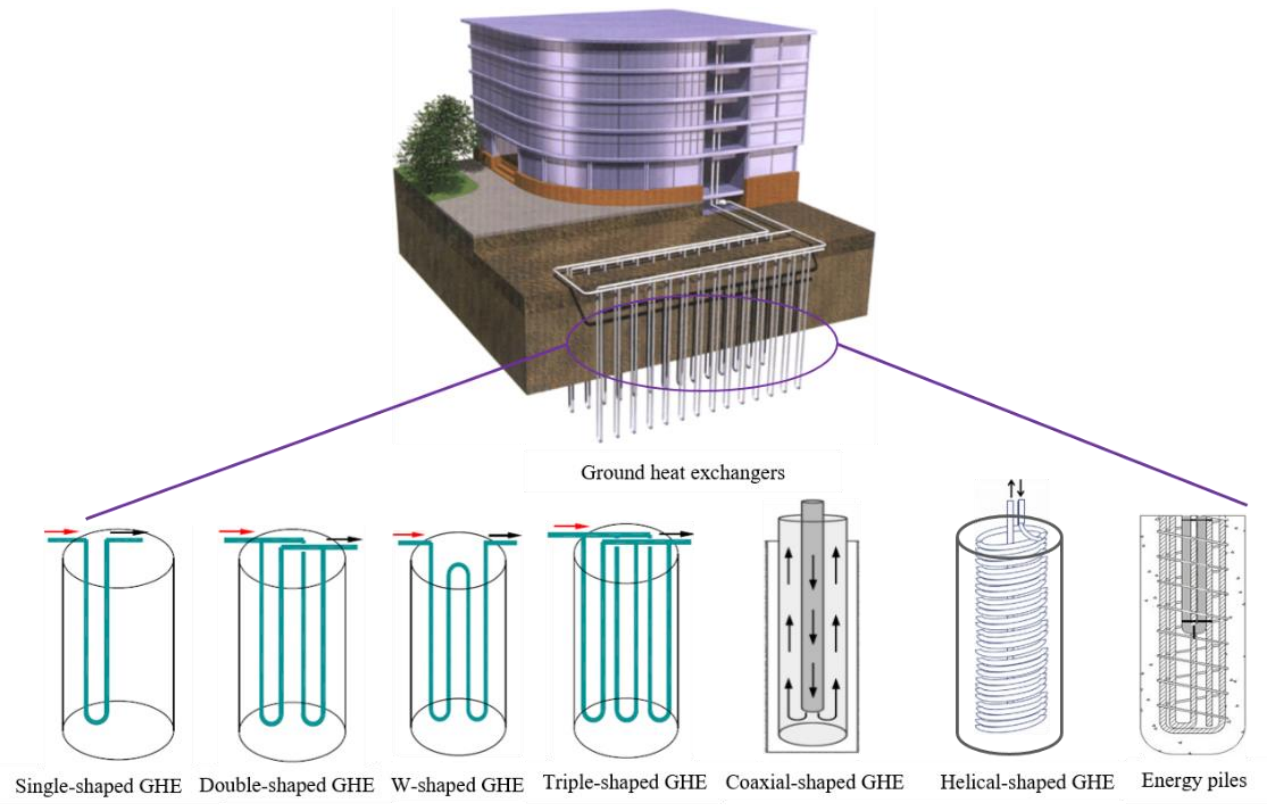

Fig. 1. The diagram of GHEs and EP [3, 4].

Bhutta et al. [7] reviewed CFD application in heat exchanger design, and showed that CFD technique is a good tool for predicting the performances of a wide variety of heat exchangers. Li and Zheng [8] developed a 3D unstructured finite-volume numerical model based on the Delaunay triangulation approach to mesh a GHE field, and found that transient analysis depends upon a short time step (one hour or less). Gustafsson et al. [9] proposed two different 3D steady-state GHE models in Scandinavia using CFD software, and discovered that the induced natural convective heat flow significantly reduces thermal resistance within a borehole heat exchanger (BHE). KoohiFayegh and Rosen [10] presented a 2D transient CFD model based on finite volume method (FVM) to investigate thermal interaction of the BHEs, and indicated that the distance between two BHEs, the heat flux from the BHE wall and the system operation time affect the thermal interaction. Khalajzadeha et al. [11] described a 3D CFD simulation model based on the second-order response surface method with the central composite design approach, and discovered that the response variables are strongly affected by the dimensionless inlet fluid temperature and pipe diameter. Bouhacinaa et al. [12] carried out a 3D computational study on the turbulent flow within a vertical GHE implemented by Fluent software, and displayed that the temperature at $2.5 \mathrm{~m}$ of depth is greater than that at $4.5 \mathrm{~m}$ by $1{ }^{\circ} \mathrm{C}$. $\mathrm{Li}[13]$ developed a 3D unstructured finite volume cumulative constant heat flux model to predict the temperature response factors on a short-term basis (one hour or less). Gashti et al. [14] proposed a 3D numerical heat transfer model based on finite element method (FEM) to assess the performance of steel pile foundation by Comsol Multiphysics package, and illustrated that temperature difference between the pile wall and inlet fluid is around $25-33 \%$, and there is a big temperature fluctuation near the tube curve. Rees and He [15] used a 3D multi-block mesh to represent BHE components for studying the fluid flow phenomena, and demonstrated that heat flux is well characterized by the mean working fluid and BHE wall temperatures when the circulating velocity 
is very high. Bouhacina et al. [16] investigated GHE thermal and dynamic properties using Fluent software, and indicated that the fins could increase heat extraction rate about $7 \%$ and enable a faster soil temperature recovery. Cao et al. [17] studied thermal performance of a novel GHE with high thermal conductivity material by using both CFD simulation and experimental test, and discovered that steel pipe has a better thermal performance in comparison to polyethylene pipe with the increasing range from $14 \%$ to $20 \%$. Dai et al. [18] established a 3D transient heat transfer CFD model for a vertical GHE by considering the effect of thermal short-circuiting between two legs of a U-tube, and demonstrated that the soil temperature field is in a "narrow belt shape". Mehrizi et al. [19] studied three EPs by using Gambit 2.4.6 and Fluent, and discovered that W-shaped-all round EP has the highest heat transfer rate in comparison to 1-Ushaped and 1-W-shaped EPs. Bezyan et al. [20] analysed thermal performances of U-, W- and spiral-shaped tubes in a pile foundation by using CFD software, and found that spiral-shaped configuration has the highest heat transfer rate and biggest inlet-outlet working fluid temperature difference. Kong et al. [21] studied thermal performances of GHE with different configurations by CFD simulation, and concluded that the mean heat transfer rate of a smooth U-tube is improved by $43 \%$ when the working fluid flow velocity increases from $0.2 \mathrm{~m} / \mathrm{s}$ to $1.2 \mathrm{~m} / \mathrm{s}$. Gashti et al. [22] simulated heating and cooling operation states of a EP system by using Comsol Multiphysics software, and observed high pile temperature fluctuations in both winter and summer operating periods. Bidarmaghza et al. [23] developed a 3D numerical model to evaluate the impact of surface air temperature for the long-term operation by using Comsol software, and revealed that accounting for the surface air temperature fluctuation could reduce GHE length up to $11 \%$ approximately.

The intermittent operating mode of GSHP would strengthen ground heat transfer and improve the system performance compared with continuous operation. This is because soil temperature recovers more quickly in the intermittent operating mode. Shang et al. [24, 25] proposed a regression formula to predict soil temperature variation under intermittent operating condition, and concluded that the soil temperature reduces more quickly and recovers more slowly when the fluid flow rate is comparatively higher and the ambient air temperature is relatively lower. Zhang et al. [26] presented an analytical solution for the intermittent running procedure by using a composite-medium line-source method, and found that the operating time and on-off ratio are critical for soil temperature recovery, and the most efficient on-off ratio ranges from 0.33 to 0.5 . Cao et al. [27] developed a GHE heat transfer model based on combination of the analytical and numerical solutions to study the soil heat accumulation nearby the GHE under five different intermittent operating modes. They indicated that the restoration performance is the best when the intermittent ratio is 3 because of the longest stopping time, and the improvement of the heat flux arising from the intermittence becomes more obvious. Gao et al. [28] compared GSHP energy efficiencies between continuous and intermittent operating modes, and discovered that the intermittent process not only improves heat exchange capacity but also decreases the number of GHEs.

A 3D finite volume model of ground source heat pump (GSHP) with multiple EPs is developed in this study by using CFD software, which is used to investigate the system thermal energy output, coefficient of performance (COP) and energy consumption. In previous researches, several numerical models of cast-in-place single EP have been proposed based on the line source [29], composite cylindrical 
1 [30, 31] and thermal resistance theories [32] to analyse EP heat transfer process. Furthermore, the helical and triple U-tube

2 configurations within the EP are also studied based on the CaRM improvement method for investigating transient heat transfer issues

3 and estimating the system thermal performance [33]. However in this study, the GSHP with multiple EPs is investigated to identify the

4 EP and its surrounding soil temperature distributions, and predict the GSHP heating performances under the continuous and intermittent

5 operating conditions through CFD software. This study will provide the clear temperature contours of multiple EPs for GSHP.

\section{Numerical mechanism}

\section{$7 \quad 2.1$ Multiple EPs}

8 In engineering practice, the EP is typically constructed by inserting one high-density polyethylene (HDPE) U-tube in an EP to serve as 9 a ground loop. This section presents multiple EPs geometrical configuration.

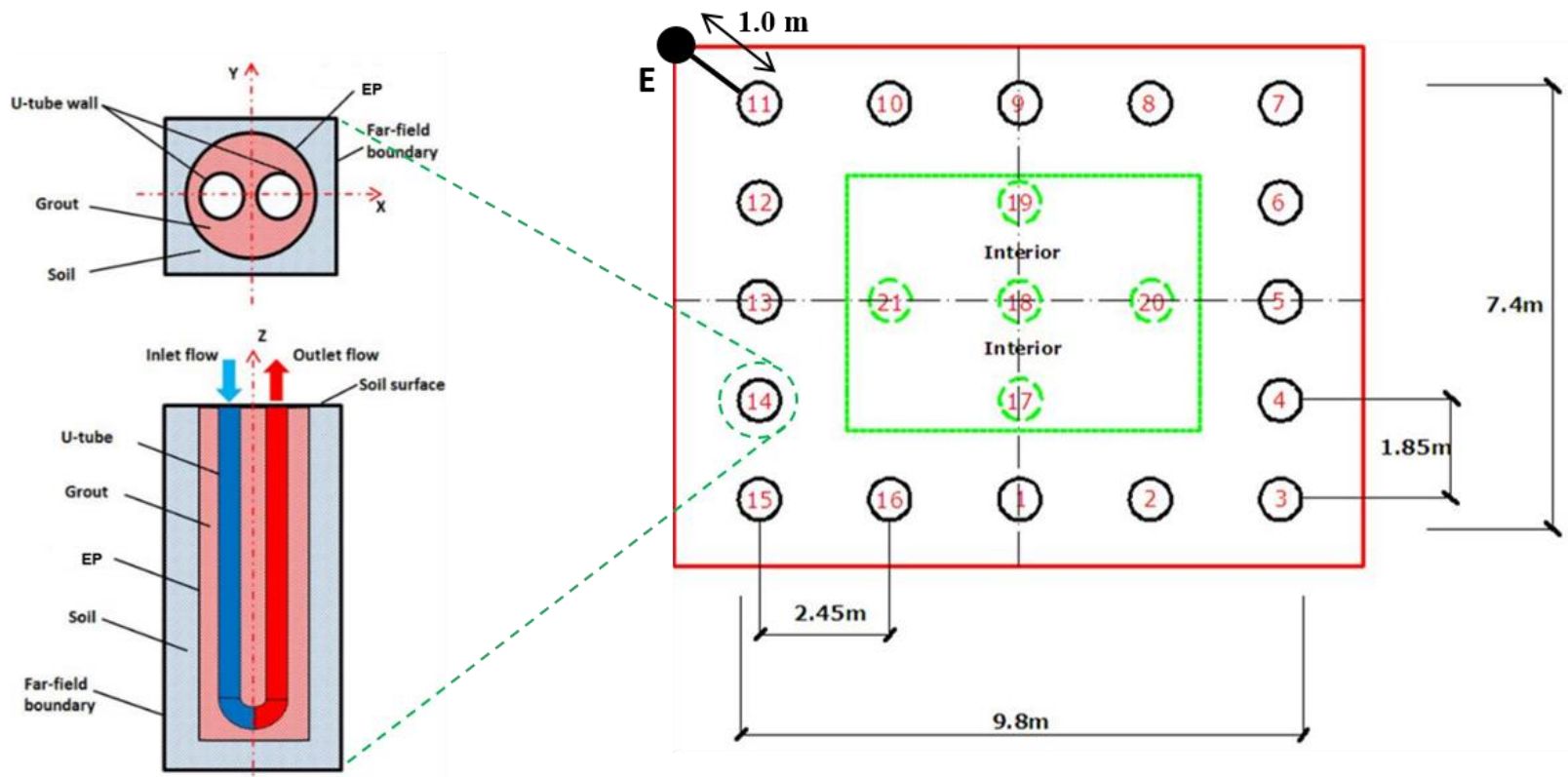

Fig. 2. A schematic diagram of the multiple EPs with single U-tube array layout.

The total pile number of is 21 , which is essential for the foundation requirement of a dwelling. However, only the perimeter 16 piles are utilized for heat exchange with soil. Each concrete pile has a diameter of $0.3 \mathrm{~m}$ and a depth of $10 \mathrm{~m}$, the inserted HDPE U-tube has an exterior diameter of $0.032 \mathrm{~m}$ with wall thickness of $0.0029 \mathrm{~m}$ and the EP shank space is $0.06 \mathrm{~m}[34,35]$. A schematic diagram of the multiple EPs is presented in Fig. 2.

2.2 Building heating energy demands and heat pump unit

The multiple EPs system is installed in a two-storey residential building in the UK. The building with the total floor area of $144 \mathrm{~m}^{2}$ is designed for one family of four persons, and its monthly heating energy requirements from November to April are shown in Fig.3 [35]. The maximum heating energy is $366.3 \mathrm{MJ}$ in December, while the minimum is 230.2 MJ in April. The EPs are connected to a 5.9 $\mathrm{kW}$ Greenline HT Plus heat pump $[34,35]$ which produces hot water at a temperature range of $35^{\circ} \mathrm{C}$ to $65{ }^{\circ} \mathrm{C}$. The main parameters of the heat pump are illustrated in Table 1. The heating operation period is from $1^{\text {st }}$ November 2007 to $29^{\text {th }}$ April 2008. 


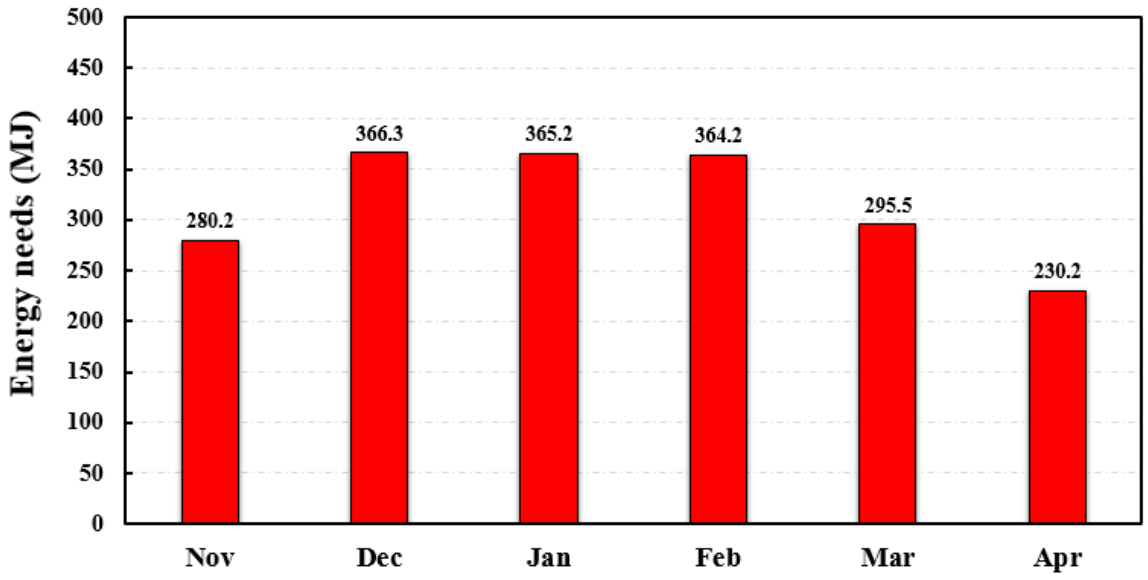

Fig. 3. Building monthly heating energy requirements.

3 Table 1 Nominal specification of Greenline HT Plus heat pump [34, 35].

\begin{tabular}{ll}
\hline Description & Value \\
\hline Emitted /Supplied output at $0 / 35^{\circ} \mathrm{C}$ & $5.9 / 1.3 \mathrm{~kW}$ \\
Emitted /Supplied output at $0 / 50^{\circ} \mathrm{C}$ & $5.4 / 1.7 \mathrm{~kW}$ \\
Minimum flow heating medium & $0.141 / \mathrm{s}$ \\
Nominal flow heating medium & $0.201 / \mathrm{s}$ \\
Superheat & $3{ }^{\circ} \mathrm{C}$ \\
Refrigerant R407C mass flow rate & $0.02 \mathrm{~kg} / \mathrm{s}$ \\
Evaporating temperature (dew point) & $-1^{\circ} \mathrm{C}$ \\
Condensing temperature (dew point) & $58.9^{\circ} \mathrm{C}$ \\
Evaporating pressure & $4.5 \mathrm{bar}$ \\
Condensing pressure & $24.7 \mathrm{bar}$ \\
\hline
\end{tabular}

4

\subsection{Mathematical modelling}

Heat transfer in the multiple EPs system is modelled as heat conduction and convection. Heat conduction takes place in the soil, BHE backfilling material (concrete) and HDPE pipe wall, and partially in the working fluid. Heat convection dominates in the working fluid circulating within the pipe. In this modelling, the working fluid flow and its heat transfer are coupled within the pipe. The coupled procedure often refers to a thermal interaction process between the conductive heat transfer of the solid region and the convective heat transfer of the fluid region. As a result, a 3D numerical model has been established and implemented using FVM based on the following assumptions:

- $\quad$ Physical properties of the working fluid are constant.

- A profile of velocity is uniform at the inlet.

- Heat transfers in the grout and soil regions are regarded as pure heat conduction and the effect of groundwater flow is negligible.

- The governing equations of the fluid flow and heat transfer are coupled numerically within the CFD software.

2.3.1 Governing equations 
1 Heat transfer within the solid region is regarded as pure heat conduction, and the corresponding energy conservation equation can be

2 given as:

$3 \quad \int_{\mathrm{V}} \frac{\partial}{\partial \mathrm{t}}(\rho \mathrm{cT}) \mathrm{dV}=\int_{\mathrm{A}}\left(\lambda \frac{\partial \mathrm{T}}{\partial \mathrm{x}}+\lambda \frac{\partial \mathrm{T}}{\partial \mathrm{y}}+\lambda \frac{\partial \mathrm{T}}{\partial \mathrm{z}}\right) \cdot \overrightarrow{\mathrm{n}} \mathrm{dA}$

4 Where, $\rho$ is the density $\left(\mathrm{kg} / \mathrm{m}^{3}\right) ; \mathrm{c}$ is the specific heat $(\mathrm{J} / \mathrm{kg} \cdot \mathrm{K})$; $\mathrm{T}$ is the temperature $(\mathrm{K})$; $\mathrm{t}$ is the time (s); $\lambda$ is the thermal conductivity

$5 \quad(\mathrm{~W} / \mathrm{m} \cdot \mathrm{K}) ; \mathrm{V}$ is the control volume $\left(\mathrm{m}^{3}\right) ; \overrightarrow{\mathrm{n}} \mathrm{dA}$ is the component of temperature in the direction of the vector $\overrightarrow{\mathrm{n}}$ normal to surface element $6 \mathrm{dA}$.

7 The fluid energy equation to illustrate the convective-conductive heat transfer is given as [36]:

$\int_{\mathrm{CV}} \frac{\partial(\rho \varphi)}{\partial \mathrm{t}} \mathrm{dV}+\int_{\mathrm{CV}} \operatorname{div}(\rho \varphi \mathrm{u}) \mathrm{dV}=\int_{\mathrm{CV}}(\Gamma \cdot \operatorname{grad} \varphi) \mathrm{dV}+\int_{\mathrm{CV}} \mathrm{S}_{\varphi} \mathrm{dV}$

9 Where, $\frac{\partial(\rho \varphi)}{\partial t}$ is the rate of change term; div $(\rho \varphi \mathrm{u})$ is the convective term; $\Gamma \cdot \operatorname{grad} \varphi$ is the diffusive term; $S_{\varphi}$ is the source term.

The transient mathematical model is applied in 3D Cartesian coordinate system by using the k- $\varepsilon$ turbulence model, thus the $\mathrm{k}$ and $\varepsilon$ conveyance equations of the standard $\mathrm{k}-\varepsilon$ turbulence model are obtained as:

$\frac{\partial(\rho \mathrm{k})}{\partial \mathrm{t}}+\operatorname{div}(\rho \mathrm{kv})=\operatorname{div}\left[\frac{\mu_{\mathrm{t}}}{\sigma_{\mathrm{k}}} \operatorname{gradk}\right]+2 \mu_{\mathrm{t}} \mathrm{S}_{\mathrm{k}} \cdot \mathrm{S}_{\mathrm{k}}-\rho \varepsilon$

$\frac{\partial(\rho \varepsilon)}{\partial \mathrm{t}}+\operatorname{div}(\rho \varepsilon \mathrm{v})=\operatorname{div}\left[\frac{\mu_{\mathrm{t}}}{\sigma_{\varepsilon}} \operatorname{grad} \varepsilon\right]+\mathrm{C}_{1 \varepsilon} \frac{\varepsilon}{\mathrm{k}} 2 \mu_{\mathrm{t}} \mathrm{S}_{\varepsilon} \cdot \mathrm{S}_{\varepsilon}-\mathrm{C}_{2 \varepsilon} \rho \frac{\varepsilon^{2}}{\mathrm{k}}$

Where, $\mathrm{k}$ is the turbulent kinetic energy per unit mass $(\mathrm{J} / \mathrm{kg}) ; \varepsilon$ is the rate of dissipation of turbulent kinetic energy per unit mass $\left(\mathrm{m}^{2} / \mathrm{s}^{3}\right)$;

$\mathrm{S}_{\mathrm{k}}, \mathrm{S}_{\varepsilon}$ are the source terms; $\sigma_{\mathrm{k}}$ and $\sigma_{\varepsilon}$ are the Prandtl numbers of $\mathrm{k}$ and $\varepsilon ; \mu_{\mathrm{t}}$ is the eddy viscosity $\left(\mathrm{m}^{2} / \mathrm{s}\right) ; \mathrm{v}$ is the fluid velocity vector; $\mathrm{C}_{\mu}, \sigma_{\varepsilon}, \sigma_{\mathrm{k}}, \mathrm{C}_{1 \varepsilon}$ and $\mathrm{C}_{2 \varepsilon}$ are the empirical constants shown in Table 2 [36].

Table 2 Turbulent constants in the governing equations.

\begin{tabular}{ccccc}
\hline $\mathrm{C}_{\mu}$ & $\mathrm{C}_{1 \varepsilon}$ & $\mathrm{C}_{2 \varepsilon}$ & $\sigma_{\mathrm{k}}$ & $\sigma_{\varepsilon}$ \\
\hline 0.09 & 1.44 & 1.92 & 1.00 & 1.30 \\
\hline
\end{tabular}

Integration of Eq. (1) over the control volume and a time interval from $t$ to $(t+\Delta t)$ gives

$\int_{\mathrm{t}}^{\mathrm{t}+\Delta \mathrm{t}} \int_{\mathrm{CV}} \operatorname{div}[\operatorname{grad}(\mathrm{T})] \mathrm{dVdt}=\int_{\mathrm{t}}^{\mathrm{t}+\Delta \mathrm{t}} \int_{\mathrm{CV}} \frac{1}{\alpha} \cdot \frac{\partial \mathrm{T}}{\partial \mathrm{t}} \mathrm{dVdt}$

Using a fully implicit formulation, the left side of the volume integral of the temporal derivative can be written as

$\int_{C V}^{t}\left[\int_{t}^{t+\Delta t} \rho c \frac{\partial T}{\partial t} d t\right] d V=\rho c\left(T_{P}-T_{P}^{0}\right) \Delta V$ 
1 Where, $\frac{\partial \mathrm{T}}{\partial \mathrm{t}}=\frac{1}{\Delta \mathrm{t}}\left(\mathrm{T}_{\mathrm{P}}-\mathrm{T}_{\mathrm{P}}^{0}\right)$ has been discretised by a first-order (backward) differencing scheme, in which $\mathrm{T}_{\mathrm{P}}^{0}$ is the value of $\mathrm{T}$ at time $\mathrm{t}$

2 and $\mathrm{T}_{\mathrm{P}}$ is the value at time $(\mathrm{t}+\Delta \mathrm{t}), \Delta \mathrm{t}$ is the time step, and $\Delta \mathrm{V}=\mathrm{dxdydz}$.

$\mathrm{I}_{\mathrm{T}}=\int_{\mathrm{t}}^{\mathrm{t}+\Delta \mathrm{t}} \mathrm{T}_{\mathrm{p}} \mathrm{dt}=\left[\xi \mathrm{T}_{\mathrm{p}}+(1-\xi) \mathrm{T}_{\mathrm{p}}^{0}\right] \Delta \mathrm{t}$

4 The fully implicit discretisation method is applied to this model, thereby the value of $\xi$ is equal to 1 . Owing to the transient term, the

5 time is subdivided into 4200 time steps of $3600 \mathrm{~s}$ which equals a time period of 180 days.

$6 \quad$ 2.3.2 Boundary and initial conditions

7 To solve the above governing equations, appropriate boundary and initial conditions must be provided. The detailed boundary and initial

8 conditions are established as follows:

9 - At $\mathrm{z}=0$, the inlet pipe temperature is equal to the fluid temperature: $\mathrm{T}_{\text {inlet }}(0, \mathrm{t})=\mathrm{T}_{\text {fluid }}(\mathrm{t})=1.2{ }^{\circ} \mathrm{C}$.

10 - The boundary condition at the outlet is regarded as zero gradient for all variables expect pressure.

11 - The soil top surface is solid with a constant temperature of $10.4{ }^{\circ} \mathrm{C}$ which is the outside air temperature.

12 - The distant and bottom surfaces are set as no-slip solid wall with a constant temperature of $15.5^{\circ} \mathrm{C}$ which is the annual average soil temperature.

- $\quad$ The working fluid flow rate is $0.5 \mathrm{~m}^{3} / \mathrm{s}$.

The main thermal physical properties of the materials are presented in Table 3.

Table 3 Summary of the primary input parameters utilized in the numerical models.

\begin{tabular}{|c|c|c|c|}
\hline \multicolumn{4}{|c|}{ Fluid (mixture of glycol and water) } \\
\hline \multicolumn{2}{|c|}{ Density } & \multicolumn{2}{|l|}{$1035 \mathrm{~kg} / \mathrm{m}^{3}$} \\
\hline \multicolumn{2}{|c|}{ Kinematic viscosity } & \multicolumn{2}{|l|}{$4.94 \times 10^{-6} \mathrm{~m}^{2} / \mathrm{s}$} \\
\hline \multicolumn{2}{|c|}{ Heat capacity } & \multicolumn{2}{|l|}{$3795 \mathrm{~J} /(\mathrm{kg} \cdot \mathrm{K})$} \\
\hline \multicolumn{2}{|c|}{ Thermal conductivity } & \multicolumn{2}{|l|}{$0.58 \mathrm{~W} /(\mathrm{m} \cdot \mathrm{K})$} \\
\hline \multicolumn{4}{|c|}{ Pipe(High density polyethylene) } \\
\hline \multicolumn{2}{|c|}{ Density } & \multicolumn{2}{|l|}{$950 \mathrm{~kg} / \mathrm{m}^{3}$} \\
\hline \multicolumn{2}{|c|}{ Heat capacity } & \multicolumn{2}{|l|}{$2300 \mathrm{~J} /(\mathrm{kg} \cdot \mathrm{K})$} \\
\hline \multicolumn{2}{|c|}{ Thermal conductivity } & \multicolumn{2}{|l|}{$0.45 \mathrm{~W} /(\mathrm{m} \cdot \mathrm{K})$} \\
\hline \multicolumn{4}{|c|}{ Filling (Grout) } \\
\hline \multirow{2}{*}{\multicolumn{2}{|c|}{$\begin{array}{l}\text { Density } \\
\text { Heat capacity }\end{array}$}} & \multicolumn{2}{|l|}{$1860 \mathrm{~kg} / \mathrm{m}^{3}$} \\
\hline & & $840 \mathrm{~J} /(\mathrm{kg} \cdot \mathrm{K})$ & \\
\hline \multicolumn{2}{|c|}{ Thermal conductivity } & \multicolumn{2}{|l|}{$2 \mathrm{~W} /(\mathrm{m} \cdot \mathrm{K})$} \\
\hline \multirow{6}{*}{ Soil } & Depth & Thermal conductivity & Density \\
\hline & Mixed Gravel and coarse sand $0 \mathrm{~m}$ to $2.22 \mathrm{~m}$ & $1.30 \mathrm{~W} /(\mathrm{m} \cdot \mathrm{K})$ & $2277 \mathrm{~kg} / \mathrm{m}^{3}$ \\
\hline & Sand gravel $2.22 \mathrm{~m}$ to $3.3 \mathrm{~m}$ & $1.15 \mathrm{~W} /(\mathrm{m} \cdot \mathrm{K})$ & $2094 \mathrm{~kg} / \mathrm{m}^{3}$ \\
\hline & Gravelly Clay $3.3 \mathrm{~m}$ to $5.5 \mathrm{~m}$ & $1.68 \mathrm{~W} /(\mathrm{m} \cdot \mathrm{K})$ & $2223 \mathrm{~kg} / \mathrm{m}^{3}$ \\
\hline & Gravelly Clay $5.5 \mathrm{~m}$ to $10 \mathrm{~m}$ & $1.75 \mathrm{~W} /(\mathrm{m} \cdot \mathrm{K})$ & $2392 \mathrm{~kg} / \mathrm{m}^{3}$ \\
\hline & Weighted mean & $1.50 \mathrm{~W} /(\mathrm{m} \cdot \mathrm{K})$ & $2260 \mathrm{~kg} / \mathrm{m}^{3}$ \\
\hline
\end{tabular}


3 A vapour-compression heat pump model is used in this study and its parametric model reflecting the effect of compressor rotation speed

4 is adopted [37].

$\mathrm{m}_{\mathrm{r}}=\mathrm{V}_{\mathrm{c}} \omega \rho_{\mathrm{r}, \text { suc }} \cdot\left[1+\mathrm{C}_{\mathrm{v}}\left(1-\frac{\mathrm{P}_{\mathrm{r}, \text { cond }}}{\mathrm{P}_{\mathrm{r}, \text { evap }}}\right)^{\frac{1}{\mathrm{n}}}\right]$

$\Delta \xi_{\text {comp }}=\xi_{\mathrm{r}, \text { dis }}-\xi_{\mathrm{r}, \text { suc }}=\frac{\mathrm{n}}{\mathrm{n}-1} \cdot \frac{\mathrm{P}_{\mathrm{r} \text { evap }}}{\rho_{\mathrm{r}, \text { suc }}} \cdot\left[\left(\frac{\mathrm{P}_{\mathrm{r}, \text { cond }}}{\mathrm{P}_{\mathrm{r}, \text { evap }}}\right)^{\frac{\mathrm{n}-1}{\mathrm{n}}}-1\right]$

$\mathrm{Q}_{\mathrm{el}}=\frac{\mathrm{m}_{\mathrm{r}} \Delta \xi_{\mathrm{comp}}}{\eta_{\mathrm{comp}}}$

8 Where, $\mathrm{m}_{\mathrm{r}}$ is the refrigerant mass flow rate $(\mathrm{kg} / \mathrm{s}) ; \mathrm{V}_{\mathrm{c}}$ is the compressor swept volume $\left(\mathrm{m}^{3}\right) ; \omega$ is the compressor rotational speed $(\mathrm{rev} / \mathrm{s})$; $\rho_{\mathrm{r}, \text { suc }}$ is the compressor suction refrigerant density $\left(\mathrm{kg} / \mathrm{m}^{3}\right) ; \mathrm{C}_{\mathrm{v}}$ is the compressor volumetric coefficient, $\mathrm{P}$ is the pressure $(\mathrm{kPa}) ; \xi$ is the specific enthalpy $(\mathrm{kJ} / \mathrm{kg}), \mathrm{n}$ is the polytropic compression coefficient; $\eta_{\text {comp }}$ is the compressor mechanical efficiency; $\Delta \xi$ is the specific enthalpy change $(\mathrm{kJ} / \mathrm{kg})$; $\mathrm{Q}_{\mathrm{el}}$ is the electrical energy consumption $(\mathrm{kW})$.

The COP of heat pump is defined as:

$\mathrm{COP}=\frac{\mathrm{Q}_{\text {heating }}}{\mathrm{Q}_{\mathrm{el}}}$

Where Qheating is the heating capacities $(\mathrm{kW})$.

2.5 Solution scheme

The geometrical model and meshing are established with a 3D domain using Gambit 2.4.6 software. Mass, momentum and energy conservations of the working fluid, pipe, pile and soil are implemented via Fluent 6.3.26. The standard k- $\varepsilon$ equations with the normal wall function are selected for the working fluid and pipe. Regarding the working fluid within the pipe, a turbulent flow is considered in this study. The turbulence kinetic energy $(\mathrm{k})$ and dissipation rate $(\varepsilon)$ are obtained by using numerical calculation based on the standard $\mathrm{k}-\varepsilon$ model in 3D Cartesian coordinate system. By applying SIMPLEC algorithm, pressure-velocity coupling in the flow region is acquired. The second-order upwind differencing scheme using multidimensional linear reconstruction is adopted to solve Navier-Stokes equations. Furthermore, convergence is deemed to be reached when the scaled residuals are less than $10^{-6}$ for energy, $10^{-5}$ for velocity and continuity and $10^{-3}$ for $\mathrm{k}$ and $\varepsilon$ equations.

2.6 Mesh analysis

The mesh quality affects the accuracy of numerical simulation result. Sparse meshes make the computation fast, but sacrificing the accuracy. Conversely, dense meshes generate the accurate simulation results, but requiring the long computational time. In order to save the computational time and gain a precise outcome simultaneously, the overall EP model is meshed with the hybrid meshes including 
1 tetrahedron, hexahedron unstructured and structured types. Figs. 4 and 5 describe the detailed meshes regarding the single and multiple

2 EPs models, respectively. Fig. 4 (a) describes the half EP involving the working fluid, pipe and pile domains, and the meshes are

3 quadrilateral with unstructured type. Fig. 4 (b) and Fig. 4 (c) present the meshes in the pipe region, meanwhile, Fig. 4 (d) displays a

4 local magnification of the meshes in U-tube bending part with triangular unstructured type. Approximately 230,000 tetrahedral elements

5 are made for single EP model. Fig. 5 (a) gives the total meshes including the soil, pile, pipe and working fluid domains, which are

6 established to complete grid independence imitation for 3D multiple EPs. More meshes are added in the soil domain nearby the EP and

7 pile domain nearby the U-tube. Thermal capacities of these cells are modified, and the fluid mass in the whole pipe is taken into account.

8 Fig. 5 (b) shows the top surface meshes which are unstructured type. The total number of cells, faces and nodes are 540,976, 11,724,100

9 and 1,088,449, respectively.

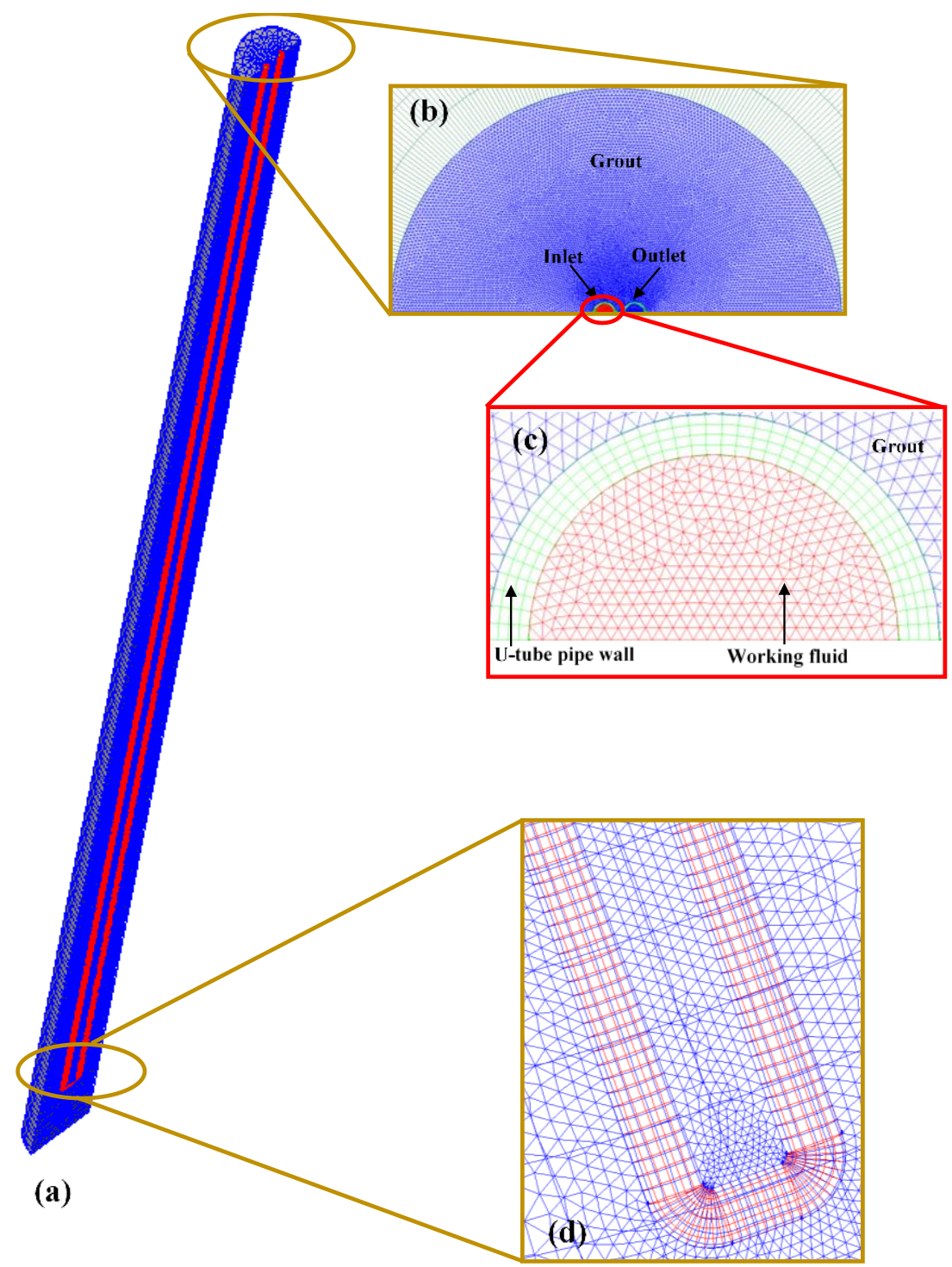

Fig. 4. Schematic diagram of the single EP model and meshes in Gambit: (a) 3D single EP model meshes; (b) meshes for the horizontal cross-section of half grout domain; (c) meshes for the horizontal cross-section of half working fluid and pipe domain; (d) meshes for the bend of U-tube pipe domain. 

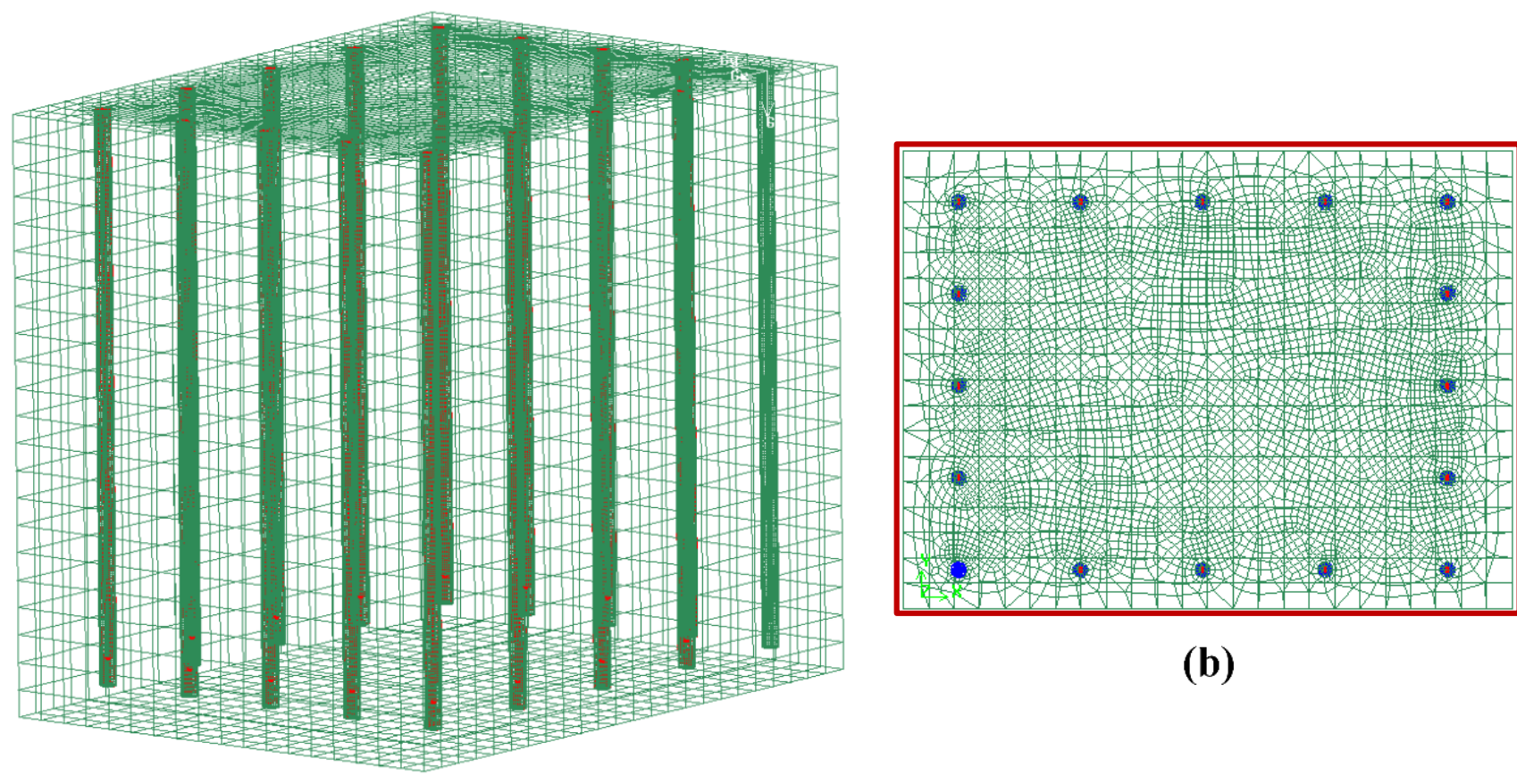

(b)

Fig. 5. Schematic diagram of the multiple EPs model and meshes in Gambit: (a) 3D multiple EPs model meshes; (b) top surface view 3 of the meshes.

\section{3. Validation}

5 In order to verify the proposed 3D model, the CFD simulation results are validated by experimental data [34], the errors are obtained 6 by Eq. (12). The experimental data gained from the facility near Birmingham, UK, are utilized in this study, the effects of main EP 7 parameters on the system performance are also analyzed.

Error $=\left|\frac{\mathrm{T}_{\text {numerical }}-\mathrm{T}_{\text {experiment }}}{\mathrm{T}_{\text {numerical }}}\right|$

\section{$9 \quad 3.1$ Pile temperatures}

The pile temperatures at a depth of $5 \mathrm{~m}$ are shown in Fig. 6, the highest pile temperature is obtained from pile 10 (referring to Fig. 2). The pile temperatures obtained from the simulation have the similar variation patterns as the experimental data, the maximum pile temperature differences between the simulation and experimental results are $4.24 \%, 5.85 \%$ and $4.36 \%$ for piles 10,11 and 12 respectively, as indicated in Table 4, the maximum errors occur at the initial operation time for piles 11 and 12 while it happens at the middle of the operation time for pile 10 . The mean temperature errors are $3.4 \%, 2.9 \%$ and $2.6 \%$ for piles 10,11 and 12 respectively, these data verify the developed model. 


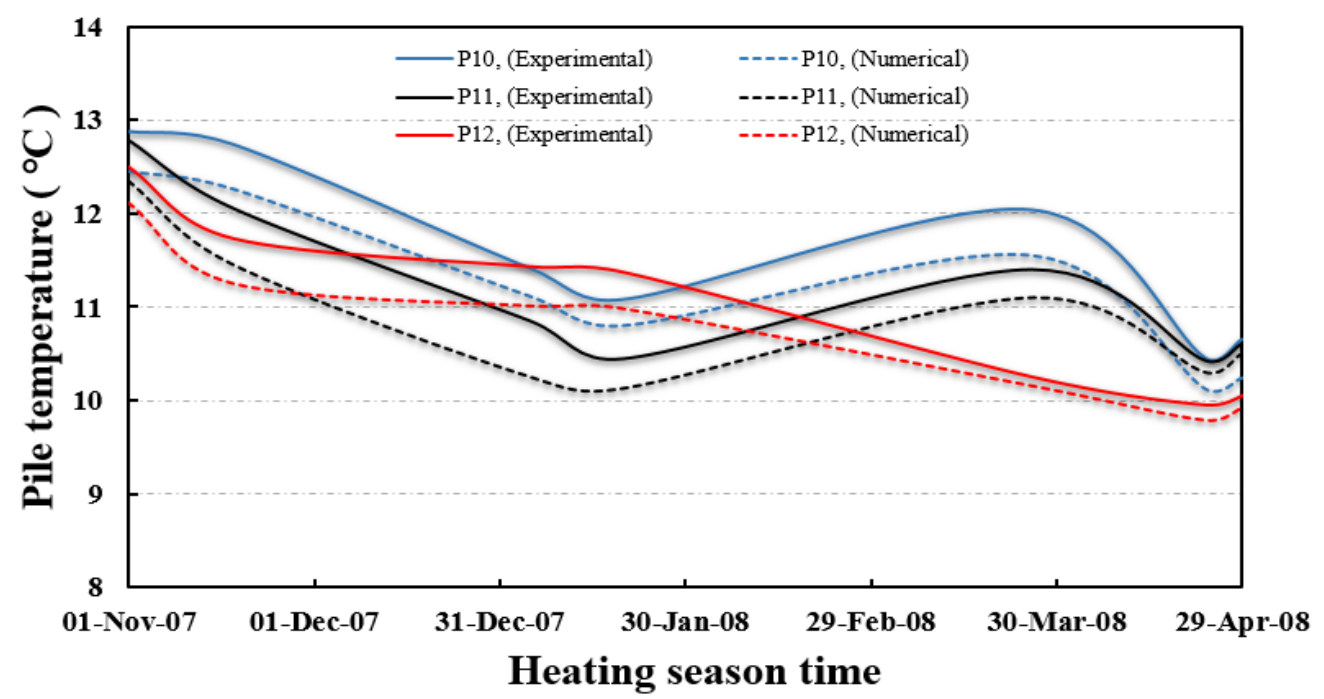

Fig.6. Pile temperatures at depth of $5 \mathrm{~m}$.

3 Table 4 Relative errors of pile temperatures.

\begin{tabular}{|c|c|c|c|}
\hline \multicolumn{4}{|c|}{ Pile 10} \\
\hline Date & CFD model results $\left({ }^{\circ} \mathrm{C}\right)$ & Test results $\left({ }^{\circ} \mathrm{C}\right)$ & Errors $(\%)$ \\
\hline $01 /$ Nov/2007 & 12.45 & 12.88 & 3.45 \\
\hline 18/Nov/2007 & 12.26 & 12.74 & 3.92 \\
\hline 05/Jan/2008 & 11.11 & 11.41 & 2.70 \\
\hline 20/Jan/2008 & 10.80 & 11.08 & 2.59 \\
\hline 26/Mar/2008 & 11.55 & 12.04 & 4.24 \\
\hline 23/Apr/2008 & 10.12 & 10.45 & 3.26 \\
\hline 29/Apr/2008 & 10.24 & 10.65 & 4.00 \\
\hline \multicolumn{4}{|c|}{ Pile 11} \\
\hline Date & CFD model results $\left({ }^{\circ} \mathrm{C}\right)$ & Test results $\left({ }^{\circ} \mathrm{C}\right)$ & Errors $(\%)$ \\
\hline 01/Nov/2007 & 12.35 & 12.78 & 3.48 \\
\hline 18/Nov/2007 & 11.45 & 12.31 & 5.24 \\
\hline 05/Jan/2008 & 10.25 & 10.85 & 5.85 \\
\hline $20 / \operatorname{Jan} / 2008$ & 10.13 & 10.45 & 3.16 \\
\hline 26/Mar/2008 & 11.10 & 11.40 & 2.70 \\
\hline 23/Apr/2008 & 10.30 & 10.43 & 1.26 \\
\hline 29/Apr/2008 & 10.50 & 10.61 & 1.05 \\
\hline \multicolumn{4}{|c|}{ Pile 12} \\
\hline Date & CFD model results $\left({ }^{\circ} \mathrm{C}\right)$ & Test results $\left({ }^{\circ} \mathrm{C}\right)$ & Errors $(\%)$ \\
\hline 01/Nov/2007 & 12.12 & 12.51 & 3.22 \\
\hline 18/Nov/2007 & 11.25 & 11.74 & 4.36 \\
\hline 05/Jan/2008 & 11.01 & 11.44 & 3.91 \\
\hline 20/Jan/2008 & 10.98 & 11.38 & 3.64 \\
\hline 26/Mar/2008 & 10.15 & 10.26 & 1.08 \\
\hline 23/Apr/2008 & 9.78 & 9.96 & 1.84 \\
\hline 29/Apr/2008 & 9.92 & 10.06 & 1.41 \\
\hline
\end{tabular}

\subsection{Soil temperatures}

The soil is typically stratified with different materials including sand, clay, rock and so on. The soil temperatures at the location E (referring to Fig. 2) are shown in Fig. 7 in which the simulation results show similar variation trends as the experimental data at $5 \mathrm{~m}$ and $10 \mathrm{~m}$ depths. The soil at $5 \mathrm{~m}$ depth has greater temperature variation compared with that at $10 \mathrm{~m}$ depth. As indicated in Fig. 7, the 
maximum soil temperature differences between the experimental and simulation results at $5 \mathrm{~m}$ and $10 \mathrm{~m}$ depths are $12.02 \%$ and $3.92 \%$ respectively, and these happen on $13^{\text {th }}$ February 2008 and $25^{\text {th }}$ November 2007, correspondingly, the mean soil temperature errors at 5 $3 \mathrm{~m}$ and $10 \mathrm{~m}$ depths are $8.75 \%$ and $2.69 \%$, respectively.

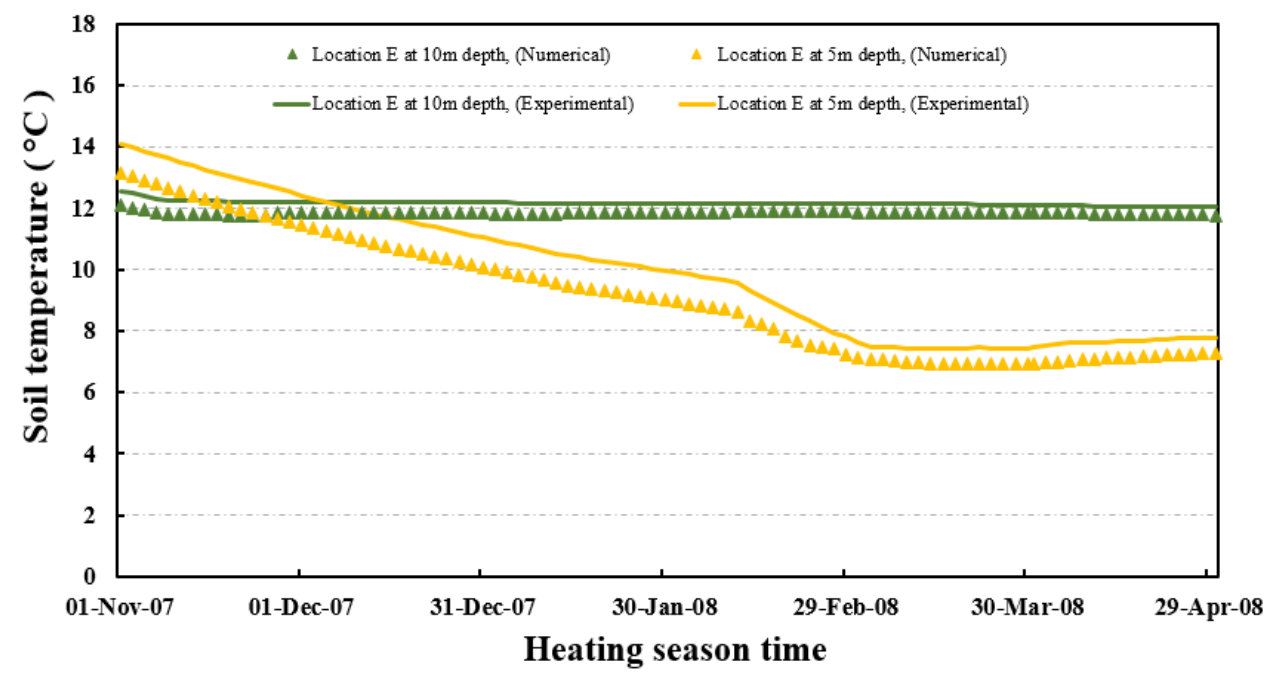

Fig. 7. Soil temperatures at location E.

These deviations could be due to the simplified assumptions in the CFD numerical model, for example, the influence of groundwater is not considered in the numerical model. The errors of the soil temperature are summarized in Table 5, it can be seen that the maximum error is $11.90 \%$ and the average error is approximately $10 \%$, therefore the CFD model is effectively supported by the experimental data.

Table 5 Relative errors of soil temperatures.

\begin{tabular}{cccc}
\hline & \multicolumn{2}{c}{ Location E at 5 m soil depth } & \\
\hline Date & CFD model results $\left({ }^{\circ} \mathrm{C}\right)$ & Test results $\left({ }^{\circ} \mathrm{C}\right)$ & Errors $(\%)$ \\
\hline 11/Nov/2007 & 13.14 & 14.10 & 7.32 \\
25/Nov/2007 & 11.76 & 12.72 & 8.18 \\
15/Dec/2007 & 10.76 & 11.72 & 8.94 \\
14/Jan/2008 & 9.49 & 10.45 & 10.14 \\
13/Feb/2008 & 8.32 & 9.31 & 11.90 \\
08/Apr/2008 & 7.07 & 7.61 & 7.61 \\
29/Apr/2008 & 7.26 & 7.82 & 7.76 \\
\hline \multicolumn{5}{c}{ Location E at 10 m soil depth } & Errors $(\%)$ \\
\hline Date & CFD model results $\left({ }^{\circ} \mathrm{C}\right)$ & Test results $\left({ }^{\circ} \mathrm{C}\right)$ & 3.80 \\
01/Nov/2007 & 12.10 & 12.56 & 3.92 \\
15/Dov/2007 & 11.74 & 12.20 & 2.96 \\
14/Jan/2007 & 11.83 & 12.18 & 2.53 \\
13/Feb/2008 & 11.87 & 12.17 & 2.27 \\
08/Apr/2008 & 11.89 & 12.16 & 2.11 \\
29/Apr/2008 & 11.83 & 12.08 & 2.11 \\
\hline
\end{tabular}

\section{Results and discussion}

4.1 Continuous operation 
1 Temperature distributions of the working fluid, pile and soil domains under the continuous operating condition are presented in Figs. 8

2 to 11 . Heat transfers among the working fluid, pile, and soil are not only along the axial direction of the EP but also along its radial

3 direction. The depth-diameter ratio of the EP is quite big and two branches of the U-tube are very close, these lead to the large

4 temperature variation in the radial direction.

\section{$5 \quad$ 4.1.1 Fluid temperatures}

6 Fig. 8 shows the schematic contours of the working fluid temperature from November to April. The temperature scale is chosen to be 7 between $275 \mathrm{~K}\left(2{ }^{\circ} \mathrm{C}\right)$ to $285 \mathrm{~K}\left(12{ }^{\circ} \mathrm{C}\right)$. The fluid temperature gradually increases along the flow direction, and its variation is more 8 intensive within the outlet branch of the U-tube compared with that within the inlet branch. It can be seen that the fluid temperature is

9 not distributed homogeneously. The contours of the static temperature display that the outlet fluid temperature increases from 276.80 $\mathrm{K}\left(3.80{ }^{\circ} \mathrm{C}\right)$ at the end of November to $281.75 \mathrm{~K}\left(8.25^{\circ} \mathrm{C}\right)$ at the end of February, then decreases to $278.95 \mathrm{~K}\left(5.45{ }^{\circ} \mathrm{C}\right)$ at the end of April.

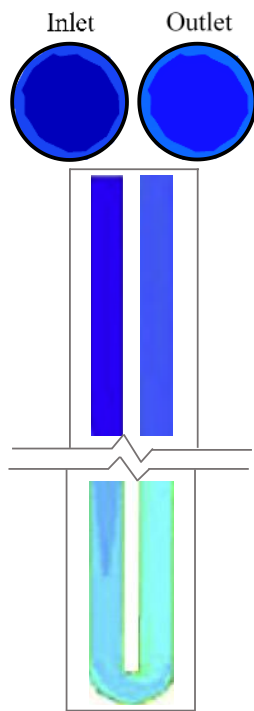

November
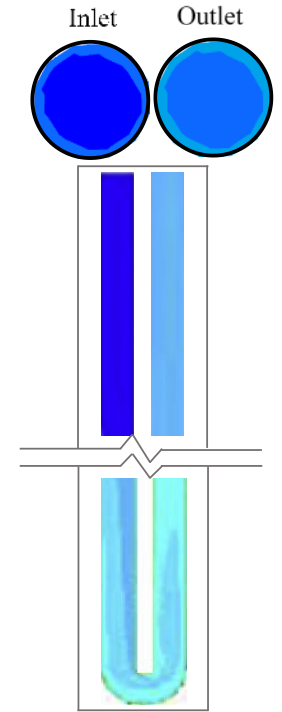

December
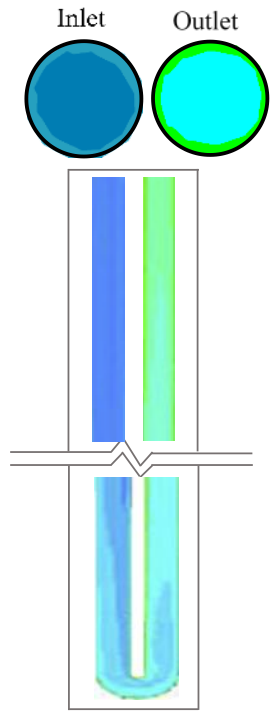

January
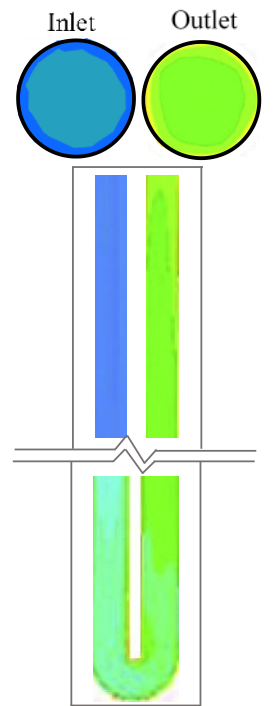

February
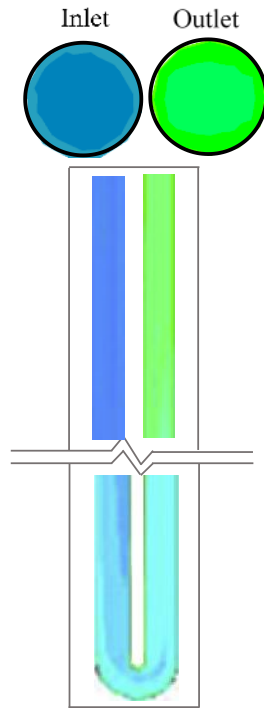

March
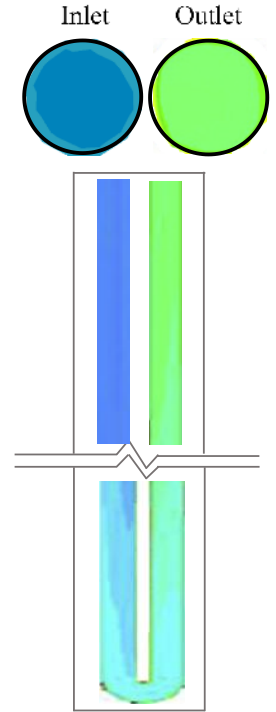

April
$2.85 \mathrm{e}+02$ $2.84 \mathrm{e}+02$ $2.83 e+02$ $2.82 \mathrm{e}+02$ $2.81 \mathrm{e}+02$ $2.80 \mathrm{e}+02$ $2.79 e+02$ $2.78 \mathrm{e}+02$ $2.77 \mathrm{e}+02$ $2.76 \mathrm{e}+02$ $2.75 \mathrm{e}+02$

Fig. 8. Contours of fluid temperature distributions.

\subsubsection{Pile temperatures}

Fig. 9 presents the pile temperature variations in the axial and radial directions, Fig. 9 (b) depicts the sectional axonometric diagram of single EP while Fig. 9 (c) gives 3D EP temperature distributions at different layers. Fig. 9 (d) and Fig. 9 (e) illustrate the temperature distributions of a single $\mathrm{EP}$ in the axial and radial directions from November to April. The temperature scale ranges from $275 \mathrm{~K}\left(2{ }^{\circ} \mathrm{C}\right)$ to $289 \mathrm{~K}\left(16{ }^{\circ} \mathrm{C}\right)$. It is found that the pile temperature dramatically reduces from $285.45 \mathrm{~K}\left(12.45^{\circ} \mathrm{C}\right)$ in November to $283.00 \mathrm{~K}\left(10.00{ }^{\circ} \mathrm{C}\right)$ in April. More heat is extracted from the EPs by the working fluid, this results in the low pile temperature nearby the U-tube. 


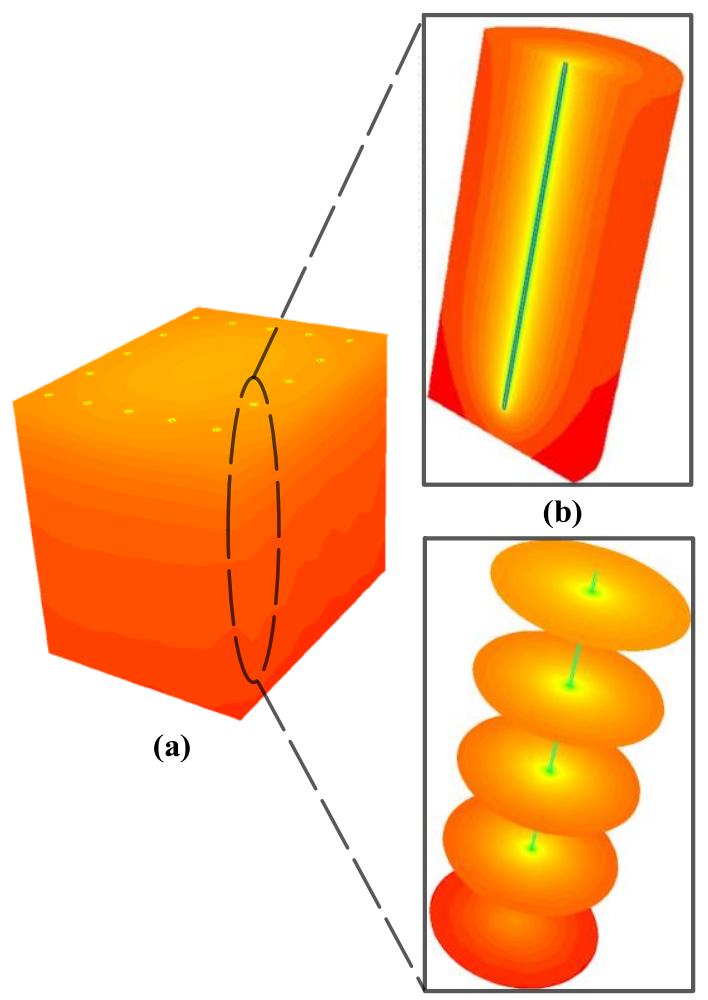

(c)
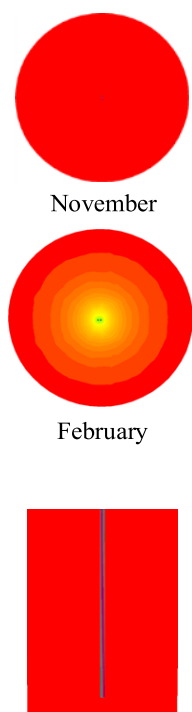

November

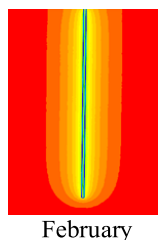

February

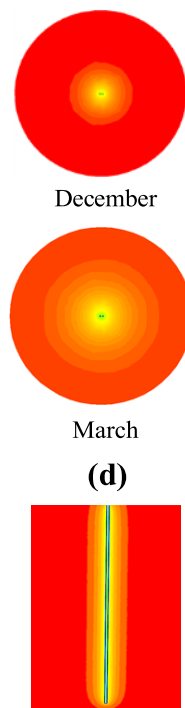

December

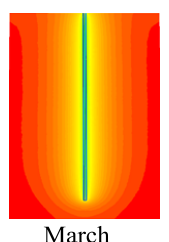

(e)

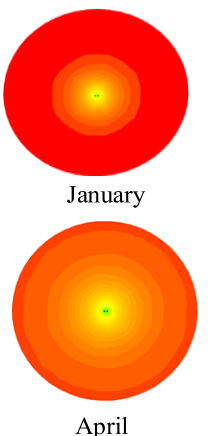

April

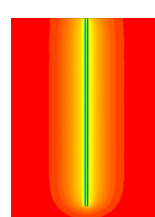

January

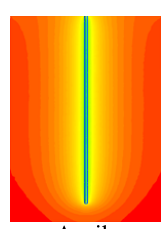

April

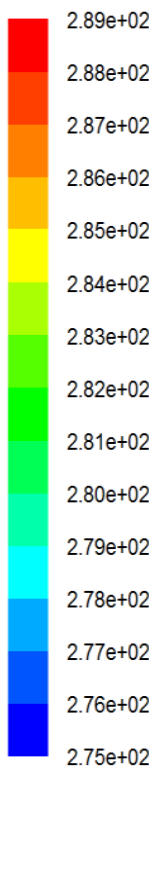

2 Fig. 9. Pile temperature distributions: (a) 3D model; (b) half an EP; (c) single EP at different depths; (d) top view of single EP; (e) single

3 EP in the axial direction.

\section{$4 \quad 4.1 .3$ Soil temperatures}

5 The soil temperature distributions from November to April are given in Figs. 10 and 11. At the initial stage, more heat is extracted from 6 the soil owing to the low inlet fluid temperature. As can be seen from Fig. 10, the largest deviation of the isotherm in the ground appears

7 in April. This is because the soil temperature decreases with operation time. 3D cutaway views regarding soil temperature distribution 8 are shown in Fig. 11 in detail, it can be seen clearly that the soil temperature nearby the EP decreases dramatically from $288.5 \mathrm{~K}\left(15.5^{\circ} \mathrm{C}\right)$

9 in November to $285 \mathrm{~K}\left(12.0^{\circ} \mathrm{C}\right)$ in April, and the temperature variation becomes smooth starting from March. 


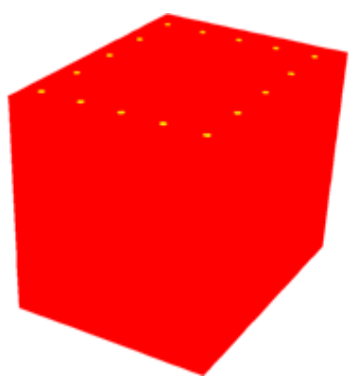

November

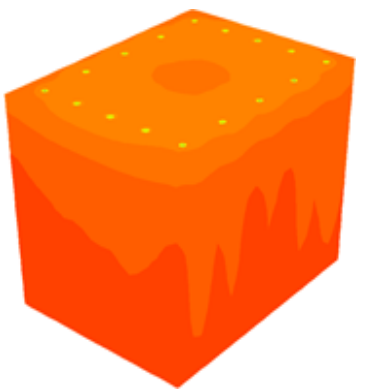

February

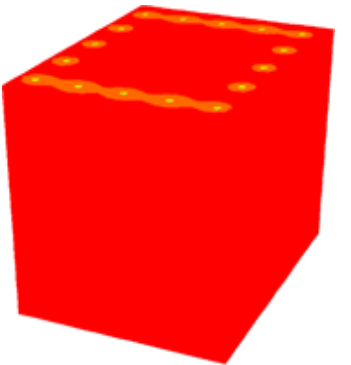

December

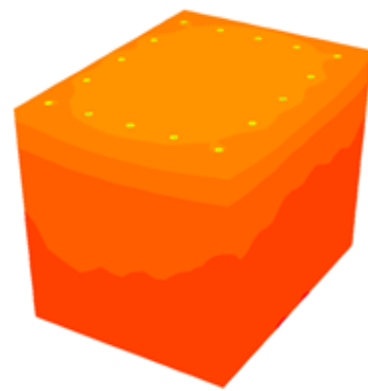

March

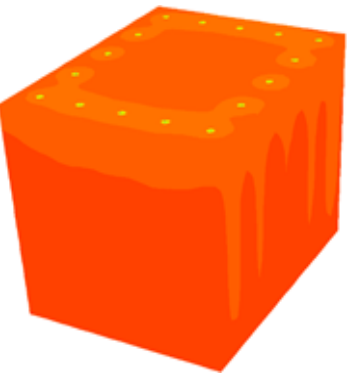

January

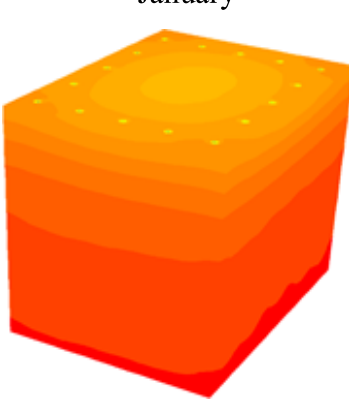

April

$2.89 e+02$

$2.88 \mathrm{e}+02$

$2.87 e+02$

$2.86 e+02$

$2.85 e+02$

$2.84 e+02$

$2.83 e+02$

$2.82 e+02$

$2.81 e+02$

$2.80 \mathrm{e}+02$

$2.79 e+02$

$2.78 \mathrm{e}+02$

$2.77 e+02$

$2.76 e+02$

$2.75 e+02$

Fig. 10. 3D soil temperature distributions.

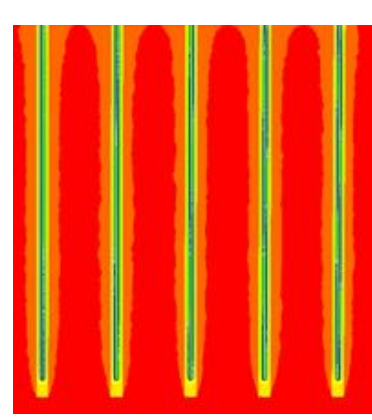

(b) December

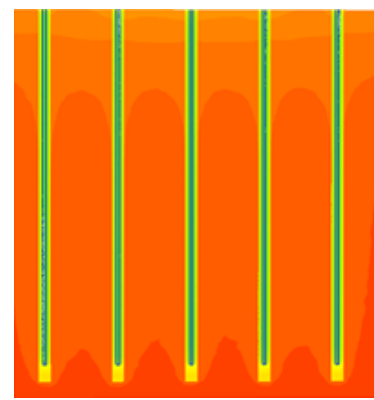

(e) March

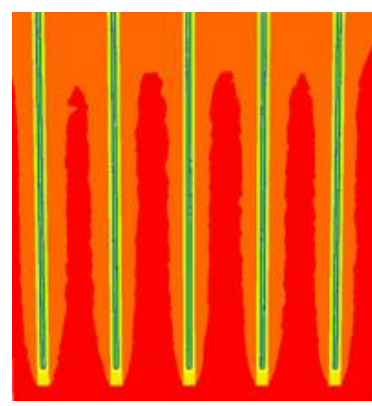

(c) January

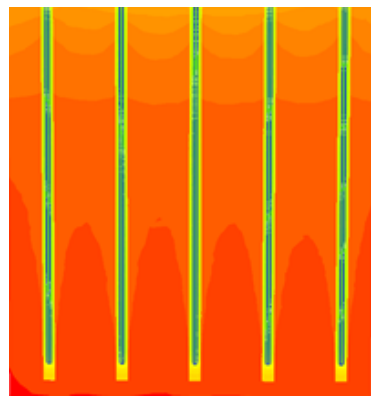

(f) April

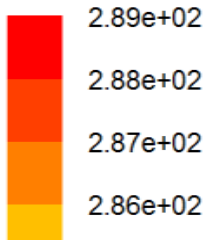

$2.85 e+02$

$2.84 e+02$

$2.83 e+02$

$2.82 e+02$

$2.81 \mathrm{e}+02$

$2.80 e+02$

$2.79 e+02$

$2.78 \mathrm{e}+02$

$2.77 e+02$

$2.76 e+02$

$2.75 \mathrm{e}+02$
3

4

6

Fig. 11. Soil temperature distributions in the axial direction.

\subsubsection{System performances}

The system daily thermal energy outputs are given in Fig. 12. It is found that the daily thermal energy outputs are lower in November and April than those in the middle period (from December to March). Notably, the system maximum daily thermal energy output is approximately $1299.6 \mathrm{MJ}$ on $17^{\text {th }}$ December 2007 and the minimum value is around $76.4 \mathrm{MJ}$ on $21^{\text {st }}$ April 2008 . 


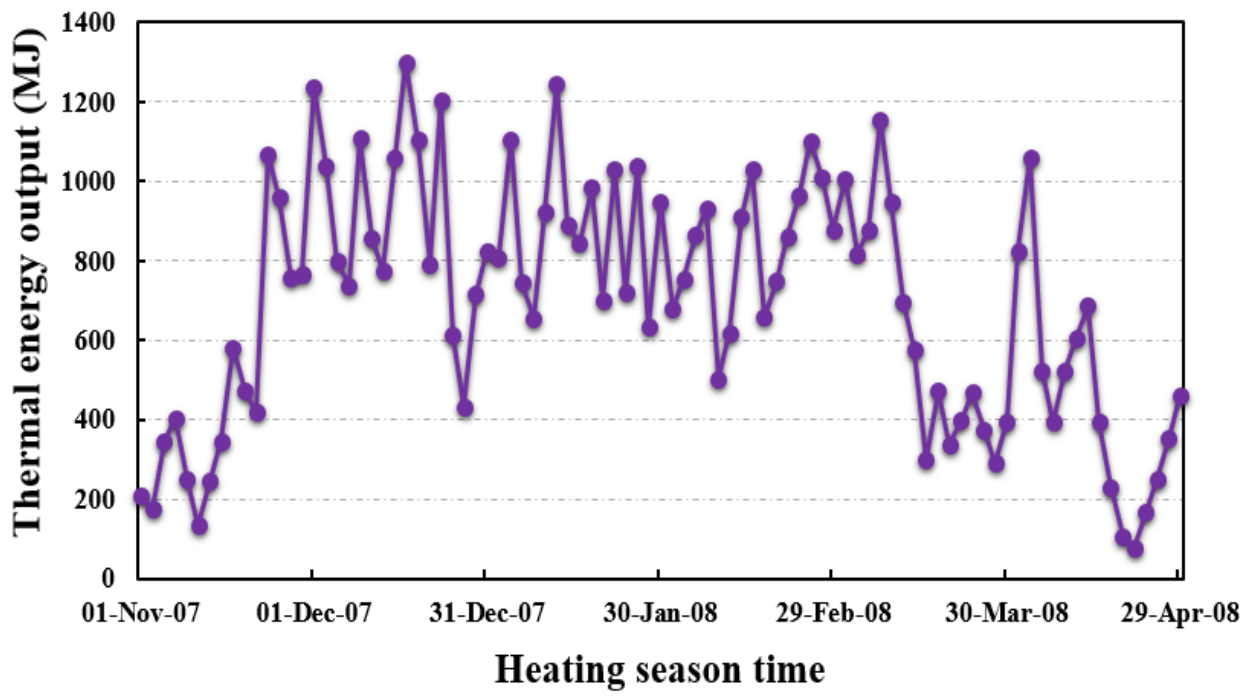

Fig. 12. Daily thermal energy outputs.

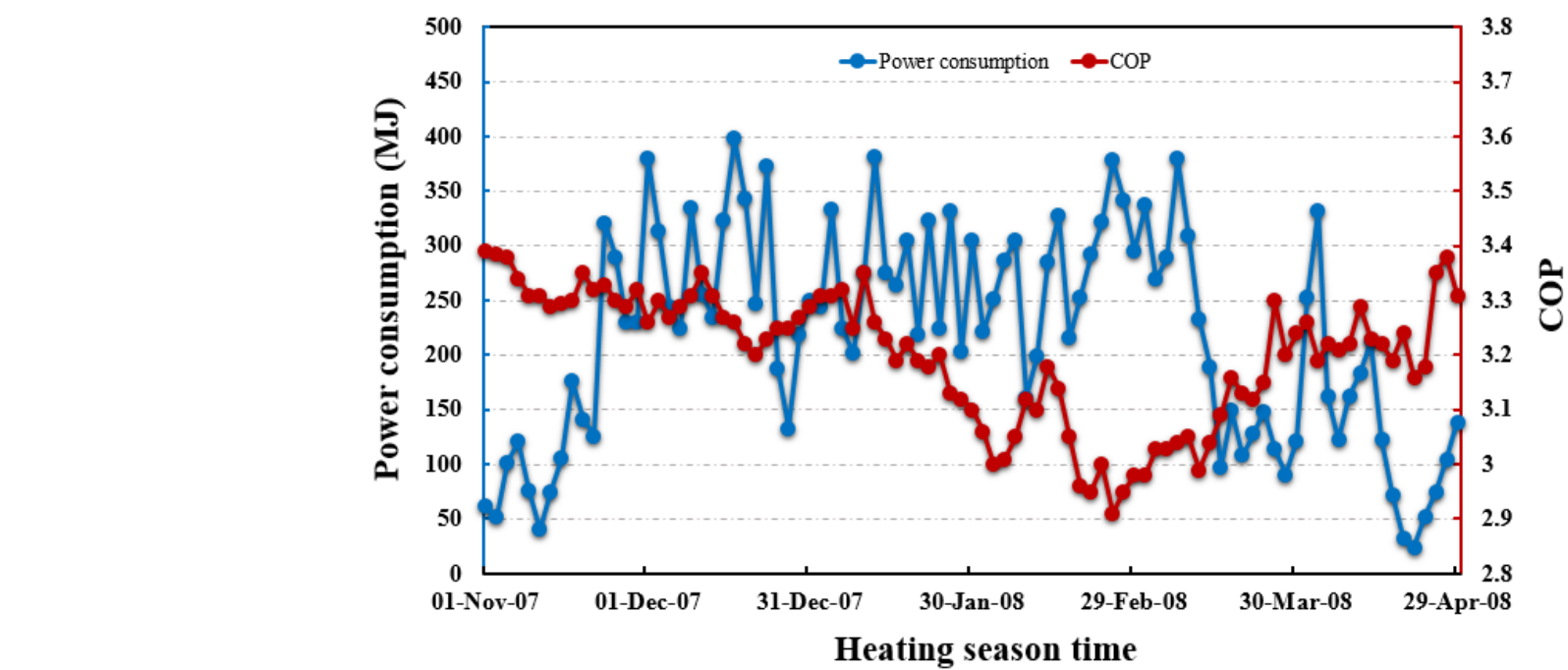

Heating season time

(1)

Fig. 13. Daily power consumptions and COPs.

Fig. 13 depicts the daily variations of the system COP and power consumption. It can be seen that the power consumption variation trend is similar to the heating load's referring to Fig. 3. The maximum daily power consumption reaches approximately $398.6 \mathrm{MJ}$ on $17^{\text {th }}$ December 2007, the mean being $218.6 \mathrm{MJ}$, while the minimum is about $24.2 \mathrm{MJ}$ on $21^{\text {st }}$ April 2008 . The maximum COP is approximately 3.39 , the average being 3.21 , while the minimum reaches around 2.91 . Some previous studies present the similar COP variations. For instance, 16 GHEs with an $80 \mathrm{~kW}$ nominal power of heat pump unit are investigated in Padua, Italy [38], and discovered that the COP varies from 3.7 to 4.5 in heating season. Furthermore, 9 GHEs with a $23.96 \mathrm{~kW}$ heating capacity heat pump are studied for an office building in Hong Kong [39], and found that COP range of 3.85 to 4.20 is obtained for this case study. 49 EPs with 171.2 $\mathrm{kW}$ nominal capacity of heat pump are simulated for one storey commercial hall building in Finland, and indicated that the average heating COP is $4.4[40]$. 
Fig. 14 shows the building heating energy demands and the system thermal energy outputs. The system thermal energy outputs far exceed the actual building heating demands, this means that the system continuous operation leads to huge waste of energy resource. Therefore, in order to avoid this problem, the system intermittent operation strategy is investigated based on the developed 3D model.

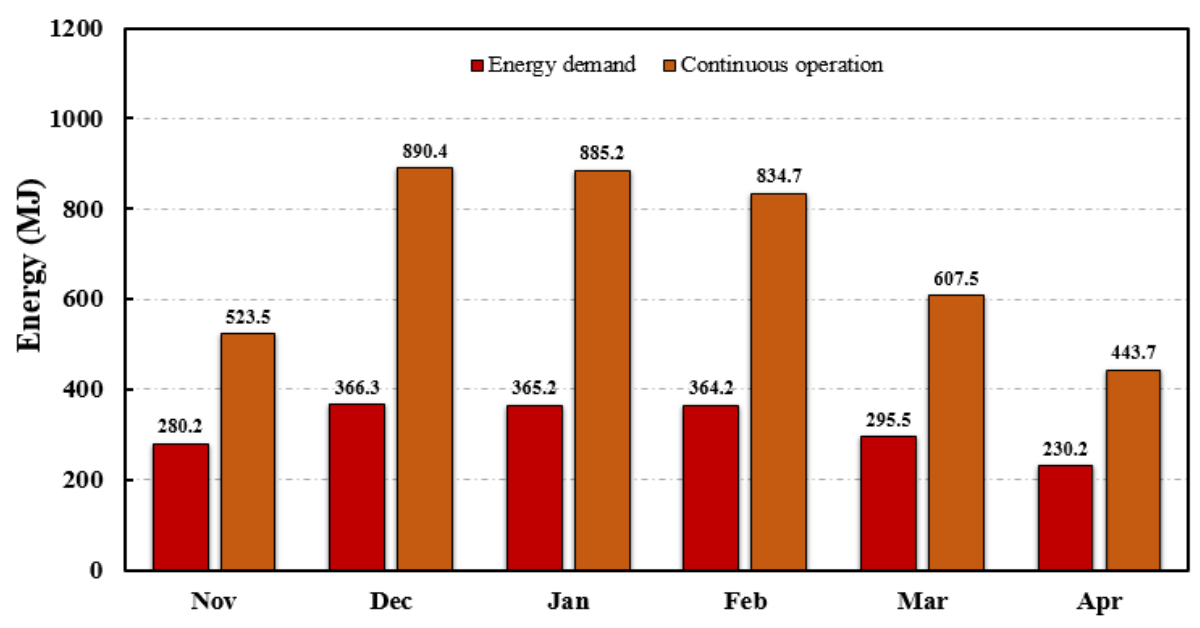

Fig. 14. Thermal energy demands and outputs.

4.2 Intermittent operation

3D numerical simulations are implemented to analyse the system performance under intermittent operating condition. Based on the data in Fig. 14, the average ratio of thermal energy output to building heating load is approximately 0.45 , which is equivalent to 10 hours of operation time per day. Thereby, in this study, $10 \mathrm{~h}$ active and $14 \mathrm{~h}$ idle mode is set as the intermittent operating strategy for assessing the system performance.

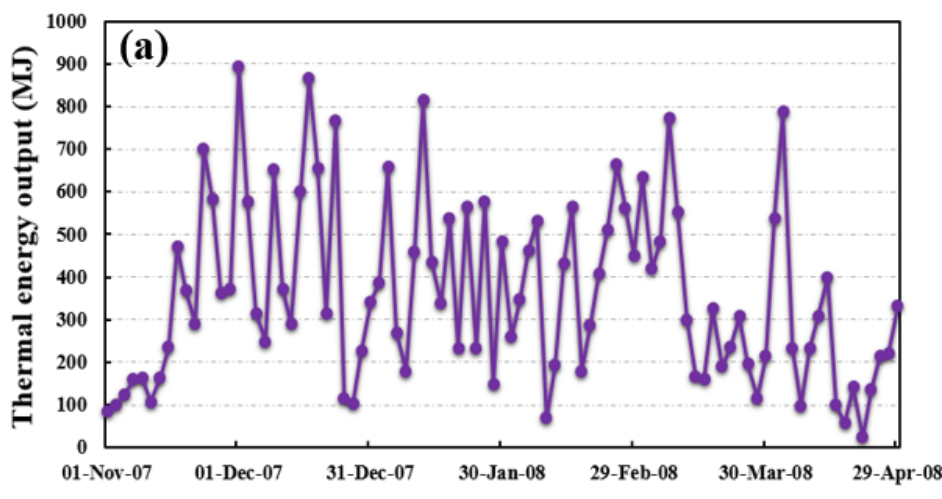

Heating season time

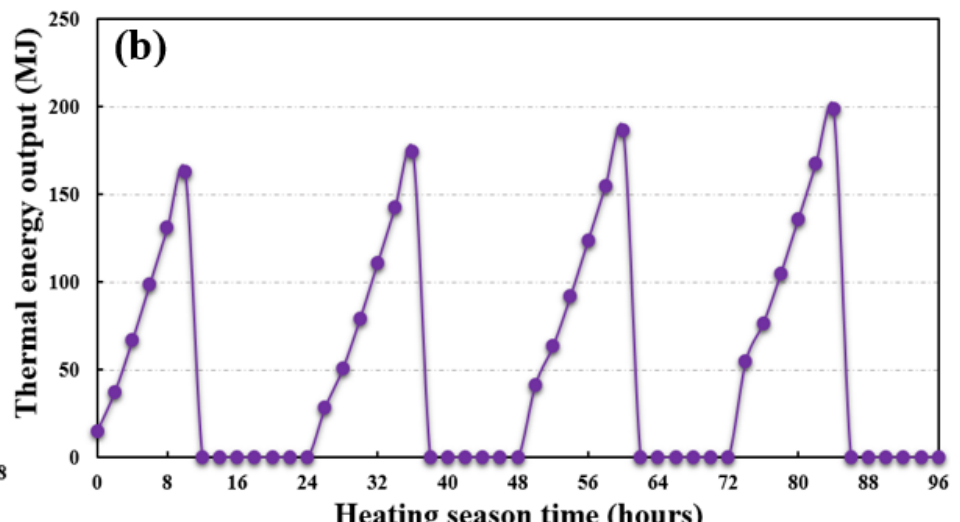

Heating season time (hours)

Fig. 15. Thermal energy outputs: (a) daily; (b) hourly in the first 4 days.

Fig. 15 (a) displays the simulation results of the daily heat pump thermal energy output for the whole heating period. As shown in this figure, the variation trend of intermittent operation is similar to the continuous operation's referring to Fig. 12. The intermittent daily thermal energy outputs are lower than those under the continuous operation condition due to the short operating time. Notably, the system maximum daily thermal energy output is approximately $892.3 \mathrm{MJ}$ on $1^{\text {st }}$ December 2007 , and the minimum value is around 23.9 MJ on $21^{\text {st }}$ April 2008. Fig. 15 (b) shows the detailed thermal energy outputs in the first 4 days, it can be seen that the system thermal 

while it is only $162.9 \mathrm{MJ}$ at the first day. This is owing to the soil temperature recovery.
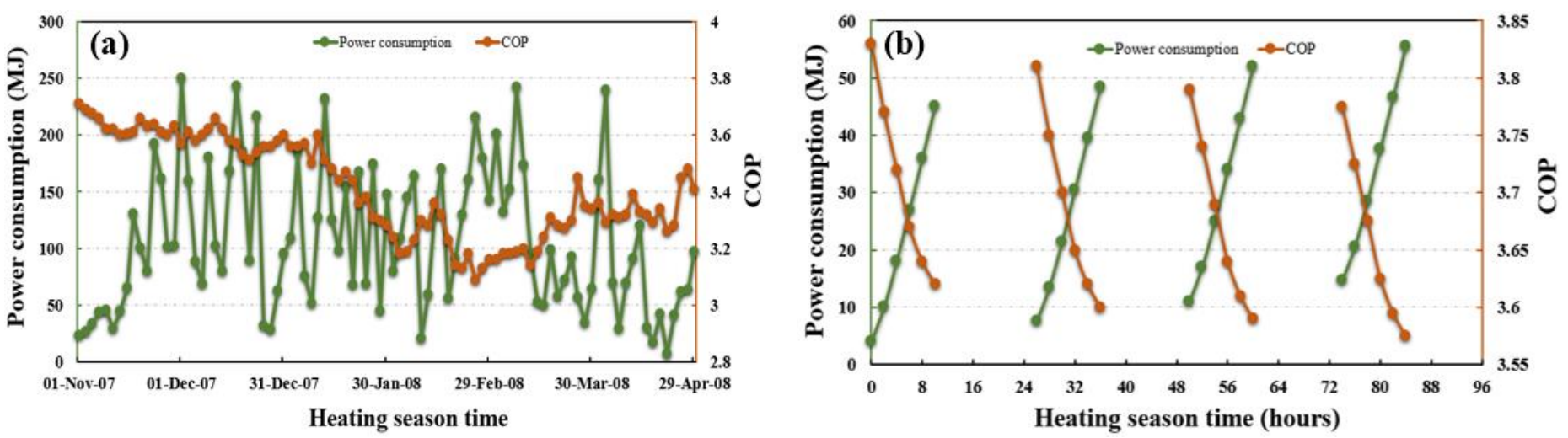

Fig. 16. COPs and power consumptions: (a) daily; (b) hourly in the first 4 days.

Fig. 16 (a) displays the system daily mean COPs and power consumptions during the intermittent operation period. Obviously, the COP variation trend of the intermittent operation is similar to the continuous operation's referring to Fig. 13. It can be found that the maximum COP is approximately 3.71, the average being 3.41, while the minimum reaches around 3.09. The intermittent COPs increase approximately $6.67 \%$ compared with those under the continuous operating condition. Meanwhile, the maximum daily power consumption approximately is $249.9 \mathrm{MJ}$ on $1^{\text {st }}$ December 2007, while the minimum value reaches $7.3 \mathrm{MJ}$ on $21^{\text {st }}$ April 2008. In comparison to the continuous operation, the daily mean power consumption under the intermittent operating condition is lower owing to the cease of the heat pump system. The detailed intermittent COP variations and power consumptions in the first 4 days are shown in Fig. 16 (b). From this figure, it can be obtained that the COP variations are fluctuant. The COPs reduce from 3.83, 3.81, 3.79 and 3.78 at the beginning of intermittence to $3.62,3.6,3.59$ and 3.58 at the end of intermittence from the first day to the fourth day, respectively. Furthermore, the power consumption variations are also fluctuant, the maximum hourly power consumption approximately reaches $45 \mathrm{MJ}$ on the first day, 48.5 MJ on the second day, $52 \mathrm{MJ}$ on the third day and 55.6 MJ on the fourth day. To sum up, both thermal energy output and power consumption gradually increase, but the heat pump COP decreases.

4.3 Comparison between the continuous and intermittent operations

Figs. 17 to 19 show monthly thermal energy outputs, COPs and power consumptions under the continuous and intermittent operations. As shown in Fig. 17, the system is capable of meeting the building heating demand under both operating conditions. As can be seen from Fig. 18, the monthly power consumptions of the heat pump are 89.5 MJ, 120.1 MJ, 121.9 MJ, 123.5 MJ, 104.9 MJ and 76.1 MJ from November to April under the intermittent operating condition, with corresponding power saves of approximately $43.4 \%, 55.9 \%$, $55.6 \%, 55.3 \%, 46.9 \%$ and $44.4 \%$, respectively, compared with those under the continuous condition. As indicated in Fig. 19, the average monthly COPs of the intermittent operating condition are higher than those of the continuous operating condition. The average monthly COPs of the intermittent operating condition are 3.63, 3.58, 3.45, 3.21, 3.25 and 3.34, with corresponding increases of 9.3\%, 9.5\%, $7.1 \%, 5.9 \%, 4.8 \%$ and $3.1 \%$, respectively, relative to the continuous operation's $(3.32,3.27,3.22,3.03,3.10$ and 3.24$)$. 


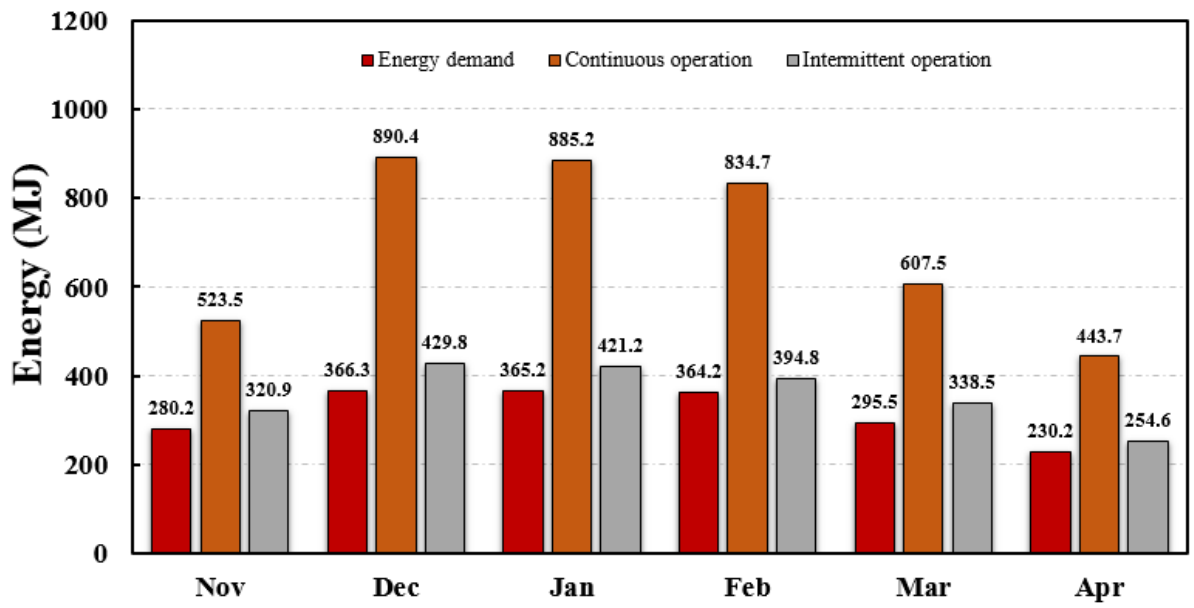

Fig. 17. Thermal energy demands and outputs under continuous and intermittent operations.

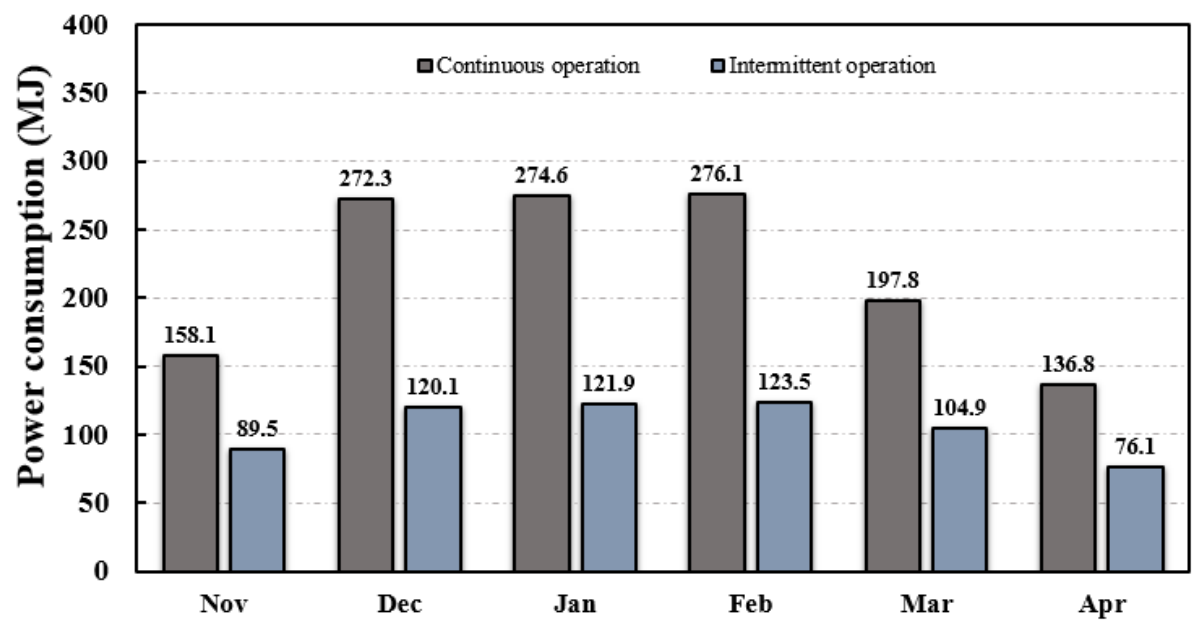

Fig. 18. The monthly power consumptions under continuous and intermittent operations.

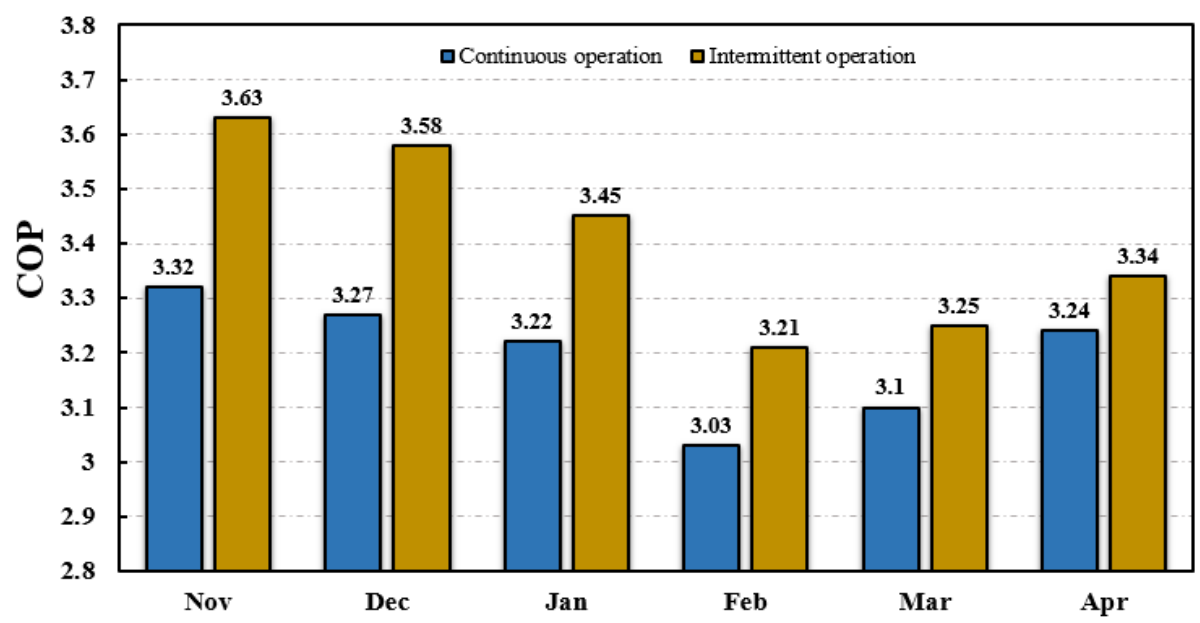

Fig. 19. The mean COPs under continuous and intermittent operations.

8 Fig. 20 illustrates the location E soil temperature variations under the continuous and intermittent operating conditions at depth of $5 \mathrm{~m}$. 9 It can be seen that the soil temperatures of the intermittent operation are higher than those of the continuous operation. This is because 
1 the soil temperature recovers when the heat pump is shut down. The soil temperature recovery not only leads to the soil heat

2 accumulation but also improves the system performance, which is very favourable for the long-term operation. The proposed

3 intermittent operating strategy does not only contribute to improving the system performance, but also avoid the waste of energy

4 resources. Some previous studies [24-28] also indicate that the optimum intermittent time is a significant factor for the GSHP system.

5 Their results show that the most efficiency on-off ratio ranges from $1 / 3$ to 1.

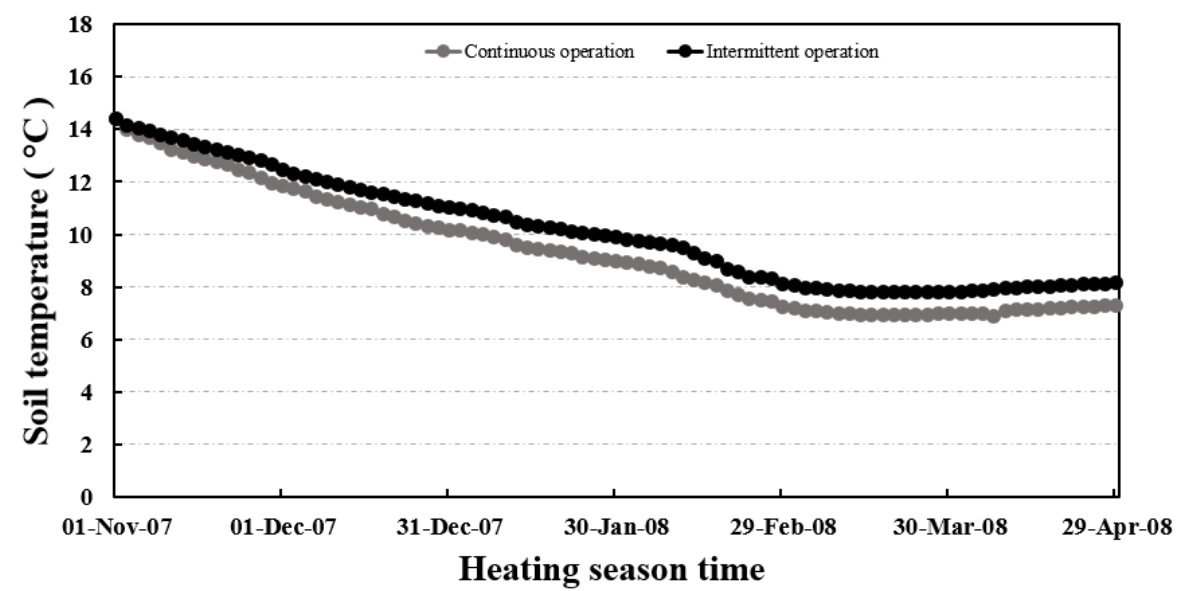

Fig. 20. The soil temperature variations.

\section{Conclusions}

A 3D finite volume model of GSHP with multiple EPs system is developed based on the CFD software in this paper. Sixteen concrete piles are adopted as heat exchangers, and a $5.9 \mathrm{~kW}$ nominal heat pump is connected with the EPs in this study. A comparison between the numerical data and experimental results shows a good agreement with less than $12 \%$ difference. The system thermal energy outputs far exceed the building heating energy demands under the continuous operating condition, so an intermittent operating strategy (10 $\mathrm{h}$ active and $14 \mathrm{~h}$ idle) is adopted to avoid energy waste and improve the system performance. Furthermore, the comparisons of monthly thermal energy outputs, COPs and power consumptions between the continuous and intermittent operating conditions are carried out. The following conclusions are drawn from this study:

(1) The system maximum thermal energy output is $1299.6 \mathrm{MJ}$ and the minimum is $76.4 \mathrm{MJ}$ under the continuous operating condition, while the maximum and minimum values under the intermittent operating condition are $892.3 \mathrm{MJ}$ and $23.9 \mathrm{MJ}$, respectively.

(2) The monthly power savings of the intermittent operating condition from November to April are $43.4 \%, 55.9 \%, 55.6 \%, 55.3 \%, 46.9 \%$ and $44.4 \%$ compared with those of the continuous operating condition.

(3) The mean monthly COPs of the intermittent operating condition are 3.63, 3.58, 3.45, 3.21, 3.25 and 3.34 from November to April, with corresponding improvements of $9.3 \%, 9.5 \%, 7.1 \%, 5.9 \%, 4.8 \%$ and $3.1 \%$ respectively, compared to the continuous operation's $(3.32,3.27,3.22,3.03,3.10$ and 3.24$)$

(4) The soil temperatures of the intermittent operation are higher than those of the continuous operation due to heat recovery for the whole operating period. 
(5) This intermittent operation gives better COP and saves more energy compared with the continuous operation. The optimum intermittent operation strategy is critical to improve the system performance.

\section{References}

[1] H. Esen, M. Inalli, Y. Esen Y, Temperature distributions in boreholes of a vertical ground-coupled heat pump system, Renewable Energy 34 (2009) 2672-2679.

[2] G. A. Akrouch, M. Sánchez, J. L. Briaud, An experimental, analytical and numerical study on the thermal efficiency of energy piles in unsaturated soils, Computers and Geotechnics 71 (2016) 207-220.

[3] J. Gao, X. Zhang, J. Liu, K. Li, J. Yang, Thermal performance and ground temperature of vertical pile-foundation heat exchanger: a case study, Apply Thermal Engineering 28 (2008) 2295-2304.

[4] Y. Hamada, H. Saitoh, M. Nakamura, H. Kukbota, K. Ochifuji, Field performance of an energy pile system for space heating, Energy and Buildings 39 (5) (2007) 517-524.

[5] A.G. Kanaris, A.A. Mouza, S.V. Paras, Flow and heat transfer prediction in a corrugated plate heat exchanger using a CFD code, Chemical Engineering \& Technology. 8 (2006) 923-930.

[6] Y. Wang, Q. Dong, M. Liu, Characteristics of fluid flow and heat transfer in shell side of heat exchangers with longitudinal flow of shell side fluid with different supporting structures, Challenges of Power Engineering and Environment (2007) 474-479.

[7] M. Bhutta, N. Hayat, M. H. Bashir, A. R. Khan, K. N. Ahmad, S. Khan, CFD applications in various heat exchangers design: a review, Applied Thermal Engineering 32 (2012) 1-12.

[8] Z. Li, M. Zheng, Development of a numerical model for the simulation of vertical U-tube ground heat exchangers, Applied Thermal Engineering 29 (2009) 920-924.

[9] A. M. Gustafsson, L. Westerlund, G. Hellström, CFD-modelling of natural convection in a groundwater-filled borehole heat exchanger, Applied Thermal Engineering 30 (2010) 683-691.

[10] S. Koohi-Fayegh, M. A. Rosen, Examination of thermal interaction of multiple vertical ground heat exchangers, Applied Energy 97 (2012) 962-969.

[11] V. Khalajzadeha, G. Heidarinejada, J. Srebric, Parameters optimization of a vertical ground heat exchanger based on response surface methodology, Energy and Buildings 43 (2011) 1288-1294.

[12] B. Bouhacinaa, R. Saima, H. Benzenineb, H.F. Oztopc, Analysis of thermal and dynamic comportment of a geothermal vertical Utube heat exchanger, Energy and Buildings 58 (2013) 37-43.

[13] Z. Li, A new constant heat flux model for vertical U-tube ground heat exchangers, Energy and Buildings 45 (2012) $311-316$. 
[14] E. H. N. Gashti, V.M. Uotinen, K. Kujala, Numerical modelling of thermal regimes in steel energy pile foundations: A case study, Energy and Buildings 69 (2014) 165-174.

[15] S. J. Rees, M. He, A three-dimensional numerical model of borehole heat exchanger heat transfers and fluid flow, Geothermics 46 (2013) $1-13$.

[16] B. Bouhacina, R. Saim, H.F. Oztop, Numerical investigation of a novel tube design for the geothermal, Applied Thermal Engineering 79 (2015) 153-162.

[17] S. Cao, X. Kong, Y. Deng, W. Zhang, L. Yang, Z. Ye, Investigation on thermal performance of steel heat exchanger for ground source heat pump systems using full-scale experiments and numerical simulations, Applied Thermal Engineering 115 (2017) $91-$ 98.

[18] L. Dai, Y. Shang, X. Li, S. Li, Analysis on the transient heat transfer process inside and outside the borehole for a vertical U-tube ground heat exchanger under short-term heat storage, Renewable Energy 87 (2016) 1121-1129.

[19] A. A. Mehrizi, S. Porkhial, B. Bezyan, H. Lotfizadeh, Energy pile foundation simulation for different configurations of ground source heat exchanger, International Communications in Heat and Mass Transfer 70 (2016) 105-114.

[20] B. Bezyan, S. Porkhial, A. A. Mehrizi, 3-D simulation of heat transfer rate in geothermal pile-foundation heat exchangers with spiral pipe configuration, Applied Thermal Engineering 87 (2015) 655-668.

[21] X. Kong, Y. Deng, L. Li, G. Gong, S. Cao, Experimental and numerical study on the thermal performance of ground source heat pump with a set of designed buried pipes, Applied Thermal Engineering 114 (2017) 110-117.

[22] E. H. N. Gashti, V. M. Uotinen, K. Kujala, Numerical modelling of thermal regimes in steel energy pile foundations: A case study, Energy and Buildings 69 (2014) 165-174.

[23] A. Bidarmaghza, G.A. Narsilio, I.W. Johnston, S. Colls, The importance of surface air temperature fluctuations on long-term performance of vertical ground heat exchangers, Geomechanics for Energy and the Environment 6 (2016) 35-44.

[24] Y. Shang, M. Dong, S. Li, Intermittent experimental study of a vertical ground source heat pump system, Applied Energy 136 (2014) 628-635.

[25] Y. Shang, S. Li, H. Li, Analysis of geo-temperature recovery under intermittent operation of ground-source heat pump, Energy and Buildings 43 (2011) 935-43.

[26] L. Zhang, Q. Zhang, M. Li, Y. Du, A new analytical model for the underground temperature profile under the intermittent operation for ground-coupled heat pump systems, Energy Procedia 75 (2015) 840-846.

[27] X. Cao, Y. Yuan, L. Sun, B. Lei, N. Yu, Yang X, Restoration performance of vertical ground heat exchanger with various intermittent ratios, Geothermics 54 (2015) 115-121. 
[28] Q. Gao, M. Li, M. Yu, Experiment and simulation of temperature characteristics of intermittently-controlled ground heat exchanges, Renewable Energy 35 (6) (2010) 1169-1174.

[29] D. Bozis, K. Papakostas, N. Kyriakis, On the evaluation of design parameters effects on the heat transfer efficiency of energy piles, Energy and Buildings 43 (2011) 1020-1029.

[30] P. Hu, J. Zha, F. Lei, N. Zhu, T. Wu, A composite cylindrical model and its application in analysis of thermal response and performance for energy pile, Energy and Buildings 84 (2014) 324-332.

[31] T.V. Bandos, A. Campos-Celador, M. Luis, L.M. Lopez-Gonzalez, J.M. Sala-Lizarraga, Finite cylinder-source model for energy pile heat exchangers: Effects of thermal storage and vertical temperature variations, Energy 78 (2014) 639-648.

[32] F. Loveridge, W. Powrie, 2D thermal resistance of pile heat exchangers, Geothermics 50 (2014) 122-135.

[33] A. Zarrella, M.D. Carli, A. Galgaro, Thermal performance of two types of energy foundation pile: Helical pipe and triple U-tube, Applied Thermal Engineering 61 (2013) 301-310.

[34] C. J. Wood, Investigation of Novel Ground Source Heat Pump, in: Built Environment, Vol. Doctor of Philosophy, University of Nottingham, 2009.

[35] C. J. Wood, H. Liu, S.B. Riffat, An investigation of the heat pump performance and ground temperature of a piled foundation heat exchanger system for a residential building, Energy 35 (2010) 4932-4940.

[36] H. K. Versteeg, W. Malalasekera, An introduction to computational fluid dynamics, the finite volume method, Pearson Prentice Hall, 2007.

[37] H. Jin, J.D. Spitler, A parameter estimation based model of water-to-water heat pumps for use in energy calculation programs, ASHRAE Transactions 108 (2002) 4493-4510.

[38] M.D. Carli, M. Tonon, A. Zarrella, R. Zecchin, A computational capacity resistance model (CaRM) for vertical ground-coupled heat exchangers, Renewable Energy 35 (2010) 1537-1550.

[39] C.K. Lee, Effect of borehole short-time-step performance on long-term dynamic simulation of ground-source heat pump system, Energy and Buildings 129 (2016) 238-246.

[40] J. Fadejev, J. Kurnitski, Geothermal energy piles and boreholes design with heat pump in a whole building simulation software, Energy and Buildings 106 (2015) 23-24.

\begin{tabular}{|ll}
\hline \multicolumn{2}{l}{ Nomenclature } \\
A & Area $\left(\mathrm{m}^{2}\right)$ \\
c & Heat capacity $(\mathrm{J} /(\mathrm{kg} \cdot \mathrm{K}))$
\end{tabular}




\begin{tabular}{|c|c|}
\hline $\mathrm{C}_{\mathrm{v}}$ & Volumetric coefficient of compressor \\
\hline $\mathrm{d}$ & Diameter (m) \\
\hline $\mathrm{h}$ & Heat transfer coefficient $\left(\mathrm{W} /\left(\mathrm{m}^{2} \cdot \mathrm{K}\right)\right)$ \\
\hline $\mathrm{H}$ & Height (m) \\
\hline $\mathrm{k}$ & Turbulent kinetic energy per unit mass $(\mathrm{J} / \mathrm{kg})$ \\
\hline $\mathrm{L}$ & Length $(\mathrm{m})$ \\
\hline $\mathrm{m}_{\mathrm{r}}$ & Refrigerant mass flow rate $(\mathrm{kg} / \mathrm{s})$ \\
\hline $\mathrm{n}$ & Polytropic compression coefficient \\
\hline $\mathrm{P}$ & Pressure $(\mathrm{kPa})$ \\
\hline $\mathrm{t}$ & Time interval (s) \\
\hline $\mathrm{T}$ & Temperature $(\mathrm{K})$ \\
\hline $\mathrm{V}_{\mathrm{c}}$ & Swept volume of compressor $\left(\mathrm{m}^{3}\right)$ \\
\hline Gree & Letters \\
\hline$\alpha$ & Ground thermal diffusivity ( $\mathrm{m}^{2} /$ day) \\
\hline$\Delta$ & Change/difference \\
\hline$\lambda$ & Ground thermal conductivity $(\mathrm{W} / \mathrm{m} \cdot \mathrm{K})$ \\
\hline$\rho$ & Density $\left(\mathrm{kg} / \mathrm{m}^{3}\right)$ \\
\hline$\varepsilon$ & $\begin{array}{l}\text { Rate of dissipation of turbulent kinetic energy per } \\
\text { unit mass }\left(\mathrm{m}^{2} / \mathrm{s}^{3}\right)\end{array}$ \\
\hline$\sigma_{\mathrm{k}}, \sigma_{\varepsilon}$ & Prandtl numbers of $\mathrm{k}$ and $\varepsilon$ \\
\hline$\mu_{\mathrm{t}}$ & Eddy viscosity $\left(\mathrm{m}^{2} / \mathrm{s}\right)$ \\
\hline$\omega$ & Rotational speed of compressor (rev/s) \\
\hline$\xi$ & Specific enthalpy $(\mathrm{kJ} / \mathrm{kg})$ \\
\hline$\Delta \xi$ & Specific enthalpy change $(\mathrm{kJ} / \mathrm{kg})$ \\
\hline$\eta$ & Efficiency $(\%)$ \\
\hline \multicolumn{2}{|c|}{ Abbreviations } \\
\hline CFD & Computational Fluid Dynamics \\
\hline $\mathrm{COP}$ & Coefficients of Performance \\
\hline
\end{tabular}




\begin{tabular}{|ll|}
\hline CV & Control Volume \\
FVM & Finite Element Method \\
GHE & Finite Volume Method \\
GSHP & Ground Heat Exchanger \\
HDPE & High Density Polyethylene \\
HP & Heat Pump \\
\hline
\end{tabular}

1 